\title{
On the mechanisms behind decadal heat content changes in the eastern subpolar gyre
}

\author{
Damien Desbruyères ${ }^{a, *}$, Herlé $^{\text {Mercier }}{ }^{a}$, Virginie Thierry $^{b}$
}

\author{
a CNRS, Laboratoire de Physique des Océans, UMR6523, IFREMER, CNRS, UBO, IRD, Plouzané, \\ France. \\ b IFREMER, Laboratoire de Physique des Océans, UMR6523, IFREMER, CNRS, UBO, IRD, \\ Plouzané, France
}

*: Corresponding author : Damien Desbruyères, tel.: +44 7895732920 ; email address : dades@noc.ac.uk

\begin{abstract}
:
Historical and modern hydrographic data show substantial decadal variability in the heat content $(\mathrm{HC})$ of the eastern subpolar North Atlantic. Those changes are here investigated in an eddy-permitting simulation (ORCA025-G70) forced by reanalysis products for the period 1965-2004. The observed and simulated decadal signal is characterized by a strong cooling in the 1960's and 1970's, a period of minor changes in the 1980's, and a strong warming in the 1990's and 2000's. A heat budget calculation is performed within a box bounded by the Greenland-Scotland sills and the Cape Farewell (Greenland)-Portugal A25-Ovide section. The decadal variability of $\mathrm{HC}$ is mainly governed by the integrated effect of anomalous oceanic heat transport across A25-Ovide $\left(H T_{A 25} \mathrm{HTA25}\right)$, with local airsea heat fluxes playing a damping role. The impact of temperature changes acting upon the mean oceanic circulation is shown to dominate the long-term behavior of $H T_{A 25} \mathrm{HTA} 25$. Through Lagrangian experiments, we show that temperature anomalies advected by the mean circulation across A25Ovide are mostly created by the gyre circulation anomalies upstream of A25-Ovide and the associated changes in the relative proportion of cold subpolar and warm subtropical waters feeding the northern and southern branches of the North Atlantic Current. These temperature anomalies induce large-scale changes in the pycnocline slope east of Reykjanes Ridge along A25-Ovide: when the NAC is relatively cold (warm), the main pycnocline moves upward (downward) in the Iceland Basin and on top of Reykjanes Ridge, thereby increasing (decreasing) the pycnocline slope. The resulting velocity anomalies lead to heat transport changes that strongly oppose the thermally-driven heat transport anomalies.
\end{abstract}

\section{Highlights}

Decadal heat content changes in the eastern subpolar gyre are mainly governed by the integrated effect of anomalous oceanic heat transport across the A25-Ovide section. Decadal trends in the full-depth heat transport at A25-Ovide are primarily governed by the advection of temperature anomalies by the mean circulation. Temperature anomalies advected by the mean currents across A25-Ovide are closely related to the varying proportion of cold subpolar waters and warm subtropical waters within the NAC. The thermally-driven heat transport across A25-Ovide is strongly damped by opposed changes in its velocity-driven component, reflecting large-scale heaving of the main pycnocline along the section. 
Keywords : North Atlantic ; Eastern Subpolar Gyre ; Heat Content ; Heat Budget ; North Atlantic Current ; Lagrangian analysis

\section{Introduction}

Understand the mechanisms governing oceanic temperature and associated heat content $(\mathrm{HC})$ variability has become an essential issue for better climatic prediction. While observational evidences from a wide range of in situ measurements show a global warming of the world oceans since several decades ( Levitus et al., 2009), the patterns of HC changes highlight significant regional disparities. Those inhomogeneities in the observed trends are particularly pronounced in the North Atlantic Ocean, where the subtropical and subpolar $\mathrm{HC}$ have evolved differently during the second half of the twentieth century: while the subtropical and tropical latitudes showed an overall heat gain, the subpolar region underwent an overall heat loss ( Lozier et al., 2008 and Zhai and Sheldon, 2012). Superimposed on this long-term trend stand decadal signals of significant amplitudes that presumably relate to changes in the large-scale oceanic circulation driven by the North Atlantic Oscil- 
lation (NAO), the dominant mode of atmospheric variability in the North Atlantic (Häkkinen, 1999; Curry and McCartney, 2001). In particular, the eastern subpolar gyre (SPG) encompasses regions where significant hydrographic changes were recently observed: the Irminger Sea, the Iceland basin and the Rockall Trough (Bersh, 2002; Holliday et al., 2008; Thierry et al,, 2008). These are key regions for the buoyancy-driven formation of intermediate and deep water masses that feed the lower limb of the so-called Meridional Overturning Circulation (e.g. Brambilla and Talley, 2008), and any long-term modifications of the upper density field there may have significant climatic implications. Through the analysis of an Ocean General Circulation Model (OGCM) simulation, the present study concentrates on the decadal variability of HC in the eastern SPG for the period 1965-2004.

Following the relatively cold and fresh period of the 1980's and early 1990's, the hydrographic content of the eastern SPG underwent a sharp warming and increase in salinity that prevailed during the 2000's (e.g. Holliday et al., 2008). The direct influence of local buoyancy fluxes at the air-sea interface was shown insufficient to explain the observed change, and the role played by the large-scale oceanic circulation consequently received much attention (e.g. Holliday, 2003; Thierry et al., 2008; Häkkinen and Rhines, 2009; de Boisséson et al., 2012). Thanks to the unprecedented spatio-temporal coverage of altimetry measurements, the post-1995 signal was shown to occur throughout a weakening of the SPG circulation, depicted in the so-called "gyre index" (Häkkinen and Rhines, 2004). Anomalous air-sea heat fluxes associated with a decreasing trend in the NAO index (Hurrell, 1995) was invoked as a dominant forcing mechanism (gray bars in Figure 2 ). In hind- 

64 nent from the Gulf Stream and a subpolar component from the Labrador

cast numerical simulations, this surface weakening of the SPG after 1995 was shown to follow an intensification from the late 1960's (Hátún et al., 2005; Böning et al., 2006), which coincides with a positive trend in the NAO index and an observed cooling/freshening of the eastern SPG (e.g. Curry and McCartney, 2001).

A closer look into the mechanisms associated with decadal hydrographic changes in the eastern SPG was documented in the study of Hátún et al. (2005). The SPG dynamics was presumed to control the respective inflows of cold/fresh subpolar waters and warm/salty subtropical waters within the North Atlantic Current (NAC). Using salinity criteria to identify their respective signatures, the authors showed opposed transport variability of both source waters that closely mimic the gyre index fluctuations: when the SPG is strong, the cold/fresh (warm/salty) water transport is strong (weak), and vice versa for a weak SPG circulation. Using an OGCM forced by NAOrelated atmospheric fields, Herbaut and Houssais (2009) excluded buoyancydriven changes of the SPG circulation as a predominant mechanism behind hydrographic changes in the eastern SPG. Instead, the authors highlighted the role played by a wind-driven anomalous circulation located over the climatological position of the Gulf Stream/NAC, the so-called "intergyre gyre" (Marshall et al., 2001; Eden and Willebrand, 2001).

More recently, modeling studies by de Boisséson et al. (2012) and Desbruyères et al. (2013) showed the power of Lagrangian diagnostics for the study of hydrographic and volume transport changes in the eastern SPG. A Lagrangian decomposition of the NAC transport into a subtropical compo- 
Current showed that hydrographic criteria were not suitable to extract the signature of both gyres from the NAC variability (Desbruyères et al., 2013). Those authors showed that the decadal variability of the NAC in the eastern SPG was accompanied by opposed transport changes of its northern and southern branches, which respectively feeds the Iceland Basin and the Rockall Trough. Importantly, this horizontal reorganization of the NAC was shown to primarily reflect a signal of subtropical origin, rather than a spinup/spin-down of the SPG circulation (Desbruyères et al., 2013). While this result complements the main conclusion of Herbaut and Houssais (2009), that is no causal relationship between the strength and shape of the SPG, the mechanisms involved in the observed hydrographic changes are still poorly documented.

The main objective of the present paper is to provide a link between the aforementioned regional circulation changes and the actual rate of change of HC in the eastern SPG. The numerical tools used are presented in Section 2 and the ability of the ORCA025-G70 simulation to reproduce the observed variability in the eastern SPG is evaluated. A heat budget calculation within a box bounded by the A25-Ovide section and the Greenland-IcelandScotland (GIS) sills (Figure 1) is then performed (Section 3). Results from the heat budget study motivates a temporal decomposition of the full-depth heat transport across A25-Ovide (Section 4), and Lagrangian experiments are carried out to complement the Eulerian analysis (Section 5). A list of concluding remarks follows (Section 6). 


\section{Numerical tools}

\subsection{The Ocean Model}

\subsubsection{General Configuration}

The study utilizes the ORCA025-G70 simulation from the global configuration ORCA025 of the Nucleus for European Modeling of the Ocean (NEMO, (Madec, 2008)) coupled with the Louvain-la-Neuve Ice model version 2 (LIM2, (Fichefet and Maqueda, 1999)). The ORCA025 numerical characteristics are fully detailed in Barnier et al. (2006). The domain is global and is configured using a tripolar grid with 1442 × 1021 grid points and a horizontal resolution that increases with latitude (from $27.75 \mathrm{~km}$ at equator to $13.8 \mathrm{~km}$ at $\left.60^{\circ} \mathrm{N}\right)$. The vertical grid consists of $46 z$-levels with vertical spacing that increases with depth (6 m near the surface, $250 \mathrm{~m}$ at the bottom). The ORCA025 parameterizations comprise a Laplacian mixing of temperature and salinity along isopycnals, a horizontal biharmonic viscosity, and a turbulence closure scheme (TKE) for vertical mixing.

A complete description of the ORCA025-G70 simulation is provided by Molines et al. (2006) and Treguier et al. (2007). It was initialized with the Polar Science Center Hydrographic T/S Climatology (PHC 3.0, Steele et al. (2001)), which consists of the Levitus 1998 climatology (Levitus et al., 1998) everywhere except in the Arctic domain where a blend of the Arctic Ocean Atlas and additional data from the Bedford Institute of Oceanography was added to produce a more realistic Arctic hydrography. The simulation was run from 1958 to 2004 with no spin-up. The forcing dataset (referenced as DFS3 by Brodeau et al. (2009)) was built using data from various origins at different frequencies. Air temperature, wind and air humidity data originate 
from the European Centre for Medium-Range Weather Forecast (ECMWF) ERA40 reanalysis for the period 1958-2001 and from the ECMWF analysis for the period 2002-2004. Daily radiative flux and monthly precipitation fields came from the Coordinated Ocean-ice Experiment (CORE) (Griffies et al., 2009) database and turbulent fluxes (wind stress, latent and sensible heat fluxes) were calculated from the CORE bulk formulae (Large and Yeager, 2004). To minimize uncontrolled drift in salinity as a response to inaccurate precipitation (Griffies et al., 2009), a global sea surface salinity (SSS) restoring to the PHC climatology was incorporated. The SSS restoring term is converted into an equivalent freshwater flux through a relaxation coefficient that was set to 0.17 meter per day. Considering the salinity evolution in the first vertical grid cell $(6 \mathrm{~m})$, the relaxation coefficient corresponded to a decay time of 36 days (Molines et al., 2006) and led to a freshwater flux of similar amplitude as the one calculated from the forcing fields. A SSS restoring under the ice cover was maintained with a 5-time enhanced coefficient. An additional restoring was also applied at the exit of the Red Sea and the Mediterranean Sea for a better representation of the overflows. The consistency of ORCA025-G70 in simulating the dynamics and hydrography of the subpolar gyre (de Boisséson et al., 2012; Desbruyères et al., 2013), strongly suggests that the following results are not significantly bias by such SSS restoring. Rattan et al. (2010) showed a strong drift in the freshwater content of the Labrador Sea during the first decade of integration in ORCA025-G70. The degree of equilibrium achieved by the late 1960's is however adequate with observations suggesting that the subsequent model variability relates to the prescribed interannual forcing (see next section). All 
the results presented in the present study are obtained with monthly model outputs and all time series presented thereafter are annual averages of the monthly time series.

\subsubsection{Model evaluation: heat content variability in the eastern SPG}

The consistency of the model temperature in the eastern SPG was recently documented by de Boisséson et al. (2010). Similar patterns of the mean surface heat fluxes in the eastern SPG from ORCA025-G70 and from reanalysis products (National Centers for Environments Prediction) were found. Accordingly, the authors highlighted the good agreement between the mean seasonal cycle of $\mathrm{HC}$ within the Iceland Basin mixed layer simulated in ORCA025-G70 and that deduced from the Argo database. Also, de Boisséson et al. (2012) showed that the mean and anomalous characteristics of the subpolar mode waters (SPMW) in the eastern SPG were satisfactorily represented in ORCA025-G70, with temperature and salinity signals in the 1990's and early 2000's in line with those reported in the observational work of Thierry et al. (2008). Additionally, they show a time series of HC anomalies averaged within the upper layers $(0-700 \mathrm{~m})$ of the whole SPG in ORCA025-G70 that closely matches a corresponding index deduced from the World Ocean Atlas 2005 (Boyer et al., 2006). Desbruyères et al. (2013) also note that the simulated structure and intensity of the horizontal and vertical circulations at A25-Ovide are fairly consistent with observational estimates based on inverse methods (Lherminier et al., 2010).

Here, the values of $\mathrm{HC}$ within the eastern SPG domain hatched in Figure 1 are calculated as follows: 


$$
H C(t)=\rho_{0} C_{p} \int_{x} \int_{y} \int_{z} \theta(x, y, z, t) d x d y d z
$$

where $\rho_{0}$ is a reference density for seawater $\left(\rho_{0}=1026 \mathrm{~kg} \mathrm{~m}^{-3}\right), C_{p}$ is the specific heat capacity $\left(C_{p}=3996 \mathrm{~kg}^{-1} \mathrm{~K}^{-1}\right)$ and $\theta$ is the three-dimensional potential temperature field. Annually-averaged anomalies of the simulated $\mathrm{HC}$ within the 0-700 m layer of the eastern SPG domain compared in Figure 2a with the corresponding observed signal computed from the World Ocean Atlas 2009 (WOA09, Levitus et al. (2009)). There is a very good agreement in the amplitude and phases of both timeseries (correlation of 0.9, significant at the $95 \%$ level). Note that all the following correlations, labelled as $r$ hereafter, are calculated from detrended annual time series and are significant at the 95\% level. Both signals describe a cooling ocean in the 1960's and 1970's followed by a period of relatively minor changes (1980's - early 1990's) and a sharp warming since the mid-1990's. Note that this warming trend prevails until 2007 in WOA09. Thus, the 1980's - early 1990's stands as a transition period between two significant switches in the eastern SPG hydrographic properties. The present study is particularly aimed to propose potential underlying mechanisms. The long-term change in HC between 1965 and 2004 for the $0-700 \mathrm{~m}$ layer amounts to $+2.210^{21} \mathrm{~J}$ in WOA09 and $0.210^{21}$ $\mathrm{J}$ in ORCA025-G70, that is much weaker than the decadal variability (this long-term trend will not be discussed in the present paper). Also shown in Figure $2 \mathrm{a}$ is the simulated $\mathrm{HC}$ change within the whole water column (thin blue line). The cooling in the 1960-1970's is slightly enhanced, possibly due to the adjustement of the deep water masses as no spin-up was performed for this simulation. Post 1980, the subsurface and full-depth signals are almost 
identical $(r=0.98)$, meaning that much of the simulated decadal changes in $\mathrm{HC}$ occured within the upper few hundred meters, in line with the observed vertical structure of decadal heat content changes in the Atlantic Ocean (Levitus et al., 2012).

A more local evaluation of the model ability to reproduce observed hydrographic changes in the eastern SPG is provided by an index of the subpolar front lateral displacements at $58^{\circ} \mathrm{N}$, in ORCA025-G70 and WOA09 (Figure 2b). We follow de Boisséson et al. (2012) and define the subpolar front position from the longitude at which the $8^{\circ} \mathrm{C}$ isotherm intersects the $200 \mathrm{~m}$ horizon (note that similar results are obtained with a surface definition of the front). The two signals are significantly correlated $(r=0.9)$ and depict a gradual eastward extension of cold subsurface waters between the mid-1960's and the mid-1990's, followed by a sharp westward retreat until the early 2000's. Finally, we note that a time-mean picture of temperature and salinity computed along A25-Ovide suggests that the time-mean deep temperature and salinity fields (including the Labrador Sea Water signature) are within the range of observational estimates (see section 2.2 in Desbruyères (2013)).

Overall, both indexes displayed in Figure 2 concur with the aforementionned studies of de Boisséson et al. $(2010,2012)$ and Desbruyères et al. (2013) to ensure that the main characteristics of the eastern SPG hydrography observed since the early 1960's are satisfactorily reproduced in ORCA025G70. The main processes involved in the heat content variability are hence presumably represented at A25-Ovide, but also in the whole subpolar gyre. 


\subsection{The Lagrangian tool}

The Lagrangian analysis tool ARIANE was extensively used in this study. Its algorithm, based on an off-line volume-preserving scheme, is described in Blanke and Raynaud (1997) and Blanke et al. (1999). Its main purpose is to calculate trajectories of numerical particles within a three-dimensional and time-dependent velocity field of an OGCM. For such calculation, the velocity field is assumed to be constant over successive periods equal to the available sampling (monthly averaged velocity field of the ORCA025-G70 simulation will be used). The resulting trajectories are interpreted as the pathways followed by small volume-conservative water parcels advected within the model velocity field from a given initial section to several final sections.

The particles are distributed along the initial section according to the archived Eulerian velocity field at each time step: particles are more numerous in regions where the incoming transport is the largest. In addition, the number of particles within each velocity grid cell was calculated in the present study so that the individual transport attributed to each particle does not exceed $0.5 \mathrm{mSv}$ (we checked that the use of a smaller value, for improved accuracy, leads to very similar results). The sum of all particle transports in each grid cell amounts to the corresponding incoming Eulerian transport. Here, the accuracy in the computation of the volume transfer between the initial and final sections is estimated to be $0.1 \mathrm{~Sv}$. Along their paths, particles will change their hydrographic properties according to the local Eulerian fields of the ocean model. Between two successive positions, the temperature and salinity of each particle therefore evolve according to the parameterized thermodynamics of the model. Supplementary information about ARIANE 
can be found at http://stockage.univ-brest.fr/ grima/Ariane/.

\section{Heat budget in the eastern Subpolar Gyre}

Having establish the ability of the ORCA025-G70 simulation to reproduce the observed changes in HC within the eastern SPG domain, a full-depth annual heat budget solving equation 2 is now presented. The annual rate of change of $\mathrm{HC}$ is balanced by the net surface heat flux and the net heat transport advection through the regional boundaries, averaged for the current year:

$$
\underbrace{\frac{\partial H C}{\partial t}}_{\Delta H C}=\underbrace{\rho_{0} C_{p} \int_{x} \int_{z} v \theta d x d z}_{O H T}+\underbrace{\int_{x} \int_{y} Q d x d y}_{S H F}+\text { residual }
$$

where $v$ is the cross-sectional velocity field and $Q$ is the surface heat flux, which includes the contributions from long/short wave radiations and sensible/latent heat fluxes. The term on the left-hand side of equation 2 is the heat content tendency $(\Delta \mathrm{HC})$, the first term on the right-hand side is the oceanic heat transport convergence (OHT) and the second term on the right-hand side is the net surface heat flux (SHF). We have verified that heat content changes induced by vertical displacements of the sea-surface were negligible. Note that a small residual term was added to close the heat budget (see below). Since we are using monthly mean temperature fields, the change in $\mathrm{HC}$ between the $1^{\text {st }}$ January and $31^{\text {st }}$ December of each year is computed using temperature values averaged for December and the following January.

Before considering the time-evolving signals shown in Figure 3, let us 
describe the equilibrium state for the period 1965-2004. The long-term mean of $\Delta \mathrm{HC}$ is nearly zero (see black line in Figure 3a). The long-term mean SHF amounts to $-0.16 \mathrm{PW}\left(1 \mathrm{PW}=10^{15} \mathrm{~J} \mathrm{~s}^{-1}\right.$, negative sign indicates heat loss to the atmosphere) with a standard deviation of $0.023 \mathrm{PW}$. The mean oceanic heat transports across the northern and southern boundaries, referred to as $\mathrm{HT}_{\text {GIS }}$ and $\mathrm{HT}_{A 25}$ hereafter, amount to $0.21 \pm 0.017 \mathrm{PW}$ and $0.38 \pm$ $0.031 \mathrm{PW}$ respectively, yielding an average OHT of $0.17 \pm 0.03 \mathrm{PW}$. Thus, a mean residual term of $-0.01 \mathrm{PW}$ has to be added to close the time-mean heat budget. This residual may partly account for diffusive isopycnal mixing across the domain boundaries, which cannot be directly estimated from the output fields of the model. As shown in Figure 3a, the contribution of this residual to $\triangle \mathrm{HC}$ is fairly small and remains relatively constant over years (green line). In addition, the use of monthly fields may lead to numerical errors due to averaging of non-linear terms, although a similar residual was obtained with 5-day averaged fields (not shown).

Annually-averaged timeseries of SHF and OHT are now related to the year-to-year heat content change $\triangle \mathrm{HC}$ (Figure 3a). Positive (negative) values for $\triangle \mathrm{HC}$ depict a warming (cooling) relative to the previous year. Integrating over time the anomalous part of SHF and OHT (Figure 3b) enables to quantify their respective contributions to the long-term heat content signal. Changes in HC are largely related to changes in $\int_{t}$ OHTdt $(r=0.93$ at 0 lag). The latter is exclusively induced by anomalous heat transport across the A25-Ovide section $\left(\mathrm{HT}_{A 25}\right)$. Variability in the heat exchanges between the eastern SPG and the Nordic seas across the GIS section $\left(\mathrm{HT}_{\text {GIS }}\right)$ is comparatively small, in line with the weak decadal variability of the density- 
overturning across the sills in ORCA025-G70 (Desbruyères et al., 2013). The impacts of $\int_{t}$ SHFdt changes are not negligible though and tend to damp the $\int_{t}$ OHTdt contribution by $\sim 40 \%$. Before 1980, negative OHT anomalies induced a cooling of $1.1310^{22} \mathrm{~J}$, while positive SHF anomalies induced a warming of $0.4410^{22} \mathrm{~J}$. After 1980, positive OHT anomalies warmed the domain by $1.1910^{22} \mathrm{~J}$ while negative SHF anomalies led to a $0.4410^{22} \mathrm{~J}$ cooling. Interestingly, $\int_{t}$ SHFdt lags HC by 1-3 years $(r=-0.7)$, suggesting that oceanic advection influences air-sea heat flux changes in the eastern SPG on decadal timescales, as already suggested by Grist et al. (2010): an increased advection of heat across the A25-Ovide section warms up the domain, thereby increasing the temperature gradient at the air-sea interface and increasing the heat loss to the atmosphere.

Overall, the aforementioned features of the heat budget variability point changes in heat advection from the Atlantic basin as the main contributor to $\mathrm{HC}$ variability in the northeastern Atlantic. We will from now concentrate on the dynamical origins of $\mathrm{HT}_{A 25}$ variability. In particular, the respective impact of local velocity anomalies versus the advection of temperature anomalies by the mean circulation will be assessed, and a Lagrangian analysis tool will be used to get more insights into the various mechanisms at play.

\section{Temporal decomposition of $\mathrm{HT}_{A 25}$}

Heat transport changes are by definition induced by either velocity or temperature changes, or by correlated anomalies in both fields. By separating the two-dimensional velocity and temperature fields at A25-Ovide into a temporal mean $(\bar{v}, \bar{\theta})$ and an anomalous part $\left(v^{\prime}, \theta^{\prime}\right)$, one can identify three 
distinct terms contributing to the variability of $\mathrm{HT}_{A 25}$. Figure 4 shows the contribution due to the advection of the mean temperature by anomalous currents (equation 3, referred to as $\mathrm{HT}_{v}$ hereafter), due to the advection of anomalous temperature by the mean currents (equation 4, referred to as $\mathrm{HT}_{\theta}$ hereafter), and due to the eddy heat flux (equation 5, referred to as $\mathrm{HT}_{e}$ hereafter).

$$
\begin{aligned}
& H T_{v}=C_{p} \rho_{0} \int_{z} \int_{x} v^{\prime} \bar{\theta} d x d z \\
& H T_{\theta}=C_{p} \rho_{0} \int_{z} \int_{x} \bar{v} \theta^{\prime} d x d z \\
& H T_{e}=C_{p} \rho_{0} \int_{z} \int_{x} v^{\prime} \theta^{\prime} d x d z
\end{aligned}
$$

(1) all heat transport time series discussed hereafter have been integrated temporally from their initial value of 1965 , and thus express a heat content in Joule. The mean eddy heat transport $\left(\mathrm{HT}_{e}\right)$ across the A25-Ovide section is estimated as $0.006 \pm 0.008 \mathrm{PW}$ and its contribution to $\mathrm{HC}$ changes is fairly small. Although this might reflect the relatively low "eddy-permitting" resolution of the ORCA025-G70 simulation $\left(\frac{1}{4}^{\circ}\right)$, Treguier et al. (2006) also found small eddy heat fluxes at A25-Ovide using a higher resolution model $\left(1 / 6^{\circ}\right)$. In fact, eddies are presumed to carry heat away from the NAC stream rather than along it (i.e. they parallel the A25-Ovide section) (Hall et al., 2004). Surprisingly, the decadal behavior of $\int_{t} \mathrm{HT}_{A 25} \mathrm{dt}$ results from a strong opposition between $\int_{t} \mathrm{HT}_{v} d t$ and $\int_{t} \mathrm{HT}_{\theta} d t$ dominated in amplitude by the temperature component. The cooling trend prior to the mid-1980's is induced 
by the advection of relatively cold water masses by the mean circulation but is significantly damped by an intensified circulation. After the mid-1980's, the mean currents advect warmer waters, but the subsequent warming of the eastern SPG is now damped by a weaker circulation, most notably between the mid 1990's and the early 2000's.

This anti-correlation between $\mathrm{HT}_{\theta}$ and $\mathrm{HT}_{v}(r=-0.9)$ strongly suggests that temperature anomalies along A25-Ovide have a strong heaving component (vertical displacement of isopycnal surfaces past a depth horizon), which creates horizontal density shears and associated geostrophic velocity anomalies. Figure 5 (top) shows the mean depth of the isopycnal surface $\sigma_{1}$ $=32.1$ along A25-Ovide, and Figure 5 (middle) shows its anomalous vertical displacements along the section between 1965 and 2004. This particular isopycnal surface is associated with the maximum of the overturning streamfunction in the density space (Desbruyères et al., 2013), and hence basically indicates a lower bound for thermocline waters in the region. It is labelled as $\sigma_{m}$ hereafter. The displacements of $\sigma_{m}$ are characterized by significant decadal fluctuations along the whole section, reaching $\pm 100 \mathrm{~m}$ on top of Reykjanes Ridge where a specific subpolar mode water is found (Thierry et al., 2008; de Boisséson et al., 2012). Most importantly, the regional changes in the depth of $\sigma_{m}$ are associated with large-scale horizontal shear in density. Prior to the 1980's, the pycnocline is deeper than average in the Iceland Basin and shallower than average in the Iberian abyssal plain, while the opposite is true from the early 1990's to the mid-2000's. To estimate the impacts on the velocity field, anomalies in the depth of $\sigma_{m}$ were spatially averaged between the top of Reykjanes ridge and $50^{\circ} \mathrm{N}$ and between $50^{\circ} \mathrm{N}$ and Portugal. The 
difference between both time series yields an index of the pycnocline slope that matches remarkably well the original (integrated) $\mathrm{HT}_{v}$ signal (Figure 6). This confirms that the advection of temperature anomalies by the mean currents drives strong cooling/warming trends in the eastern SPG (reflected in $\mathrm{HT}_{\theta}$ ), and contributes to their damping via the setup of geostrophic velocity anomalies (reflected in $\mathrm{HT}_{v}$ ).

Having established the link between the two main components of the heat transport across A25-Ovide and having highlighted the advection of temperature anomalies by the mean currents as a crucial mechanism, the following section is concerned with the large-scale formation of these anomalies and the associated forcing. As suggested in several studies, hydrographic changes in the eastern SPG are tightly linked to upstream changes in the large scale oceanic circulation (e.g. Bersh, 2002; Holliday et al., 2008; Thierry et al., 2008). Some underlying mechanisms were recently detailed in the modelling study of Desbruyères et al. (2013). Combining the present ORCA025-G70 simulation and a Lagrangian analysis tool to investigate the changing composition of the NAC, the authors documented a northward shift of subtropical waters along A25-Ovide as one moves from the low NAO-period of the 1970's to the high NAO period of the 1990's. The contribution of this changing horizontal circulation to the temperature variability north of A25-Ovide was however not quantified. In the following section, we perform similar Lagrangian diagnosis to investigate the underlying processes of temperature changes along A25-Ovide. By providing additional information on the distinct water masses crossing A25-Ovide that are not available in the Eulerian framework (spatial origins, source temperatures, volume transports), the La- 
372

grangian analysis stands as a robust and suitable method for linking the local variability at A25-Ovide to the basin-scale gyre variability (Burkholder and Lozier, 2011; de Boisséson et al., 2012; Desbruyères et al., 2013).

\section{A Lagrangian analysis of temperature changes within the NAC}

\subsection{Reconstructing the $H T_{\theta}$ signal with ARIANE}

To identify the major mechanisms that led to the formation of the temperature anomalies upstream of A25-Ovide, the thermally-driven heat transport $\mathrm{HT}_{\theta}$ (equation 4) is reconstructed using the Lagrangian analysis tool ARIANE. Let us recall before proceeding that the local velocity field at A25-Ovide is kept constant in the calculation of $\mathrm{HT}_{\theta}$, but that temperature anomalies observed at A25-Ovide are likely to result from changes in the circulation upstream of the section.

The Lagrangian experiments are performed within a domain bounded by the A25-Ovide section, a subpolar transect at the exit of the Labrador Sea (SPG section) and a subtropical transect at $39^{\circ} \mathrm{N}$ (STG section) (see Figure 1). Every month between 1965 and 2004, hundred thousands of numerical particles are initially positioned along A25-Ovide over the whole water column. The numerical particles are advected backward in time by the threedimensional model velocity field and their trajectories are integrated until they leave the domain through one of the three defined sections (STG, SPG and A25-Ovide). The integration is done during a 7-year period to ensure that a large majority of particles ultimately reach a final section (only $1 \%$ of the initial particles stay within the domain, on average). The temporal backward integration allows the circulation across A25-Ovide, which is now 
reduced to water masses flowing out of the study domain, to be decomposed into a subtropical contribution from the Gulf Stream and a subpolar contribution from the Labrador Sea. The sum of both contributions is here considered as a proxy for the NAC transport. The time-mean (1965-2004) total transports of the subtropical and subpolar components of the NAC at A25-Ovide are $18 \mathrm{~Sv}$ and $22 \mathrm{~Sv}$, respectively, as shown in Figure 7 which displays their respective horizontal streamfunctions. Note that the sum of both contributions $(40 \mathrm{~Sv})$ is in line with the mean intensity of the barotropic circulation seen in many OGCM simulations (e.g. Eden and Willebrand, 2001; Treguier et al., 2006; Deshayes and Frankignoul, 2008). Note also that the spatial structure of the NAC along A25-Ovide simulated in ORCA025-G70 has been validated against observational estimates in Desbruyères et al. (2013).

To reconstruct the two-dimensional temperature field at A25-Ovide, the seeded particles are initially grouped into bins collocated on the original model grid cell. Using outputs of the backward integration for each monthly experiments, the particle population within each bin can be decomposed into a subtropical group from $39^{\circ} \mathrm{N}$ with a relative volume $\%_{S T G}$ and a source temperature $\theta_{S T G}$, and a subpolar group from the Labrador Sea with a relative volume $\%_{S P G}$ and a source temperature $\theta_{S P G}$. These four variables are then combined to obtain a Lagrangian estimation of the two-dimensional temperature field along the A25-Ovide section:

$$
\theta_{A 25}=\%_{S T G} \theta_{S T G}+\%_{S P G} \theta_{S P G}+\Delta \theta
$$

$\theta_{S T G}$ and $\theta_{S P G}$ respectively refer to temperature measured along the STG and SPG sections. Hence, a residual term $\Delta \theta$ accounts for temper- 
ature changes of the subtropical/subpolar water mass between the subtropical/Labrador transects and the A25-Ovide section, through air-sea heat fluxes and mixing with water masses other than those sampled by the STG and SPG particles. An example of such temperature calculation using ARIANE for a given bin is provided in Figure 8. The Lagrangian $\mathrm{HT}_{\theta}$ at A25Ovide is simply computed by using expression 6 for $\theta_{A 25}$ in equation 4 . The resulting (integrated) timeseries is compared in Figure 9 with the corresponding Eulerian signal. The main discrepancies between both signals is a slight lag in the Lagrangian time series after the mid-1980's, and an overall weaker amplitude. We verified that these errors were due to the aforementioned approximation in the reconstruction: the southward export of temperature anomalies across the section (within the western boundary current off Greenland for instance) are not included in the calculation which is focused on the northward flowing NAC. However, the Eulerian and Lagrangian signals are strongly correlated $(r=0.95)$ and the latter captures the major trends we are interested in.

\subsection{Decomposing the Lagrangian $H T_{\theta}$}

In this section, we decompose the variability of $\theta_{A 25}$ into three main mechanisms, and quantify their respective impacts on $\mathrm{HT}_{\theta}$ at A25-Ovide. Decomposing each variable of equation 6 into its mean and anomalous part and after neglecting the cross terms, anomalies in $\theta_{A 25}$ can be expressed as:

$$
\theta_{A 25}^{\prime}=\overline{\%_{S T G}} \theta_{S T G}^{\prime}+\overline{\%_{S P G}} \theta_{S P G}^{\prime}+\%_{S T G}^{\prime} \overline{\theta_{S T G}}+\%_{S P G}^{\prime} \overline{\theta_{S P G}}+\Delta \theta^{\prime}
$$


440

442

With regards to expression 7 , the three mechanisms involved in the variability of $H T_{\theta}$ are:

(1) changes in the temperature of the two source waters as they leave the subtropics and the Labrador Sea, computed respectively as:

$$
H T^{S u b t}=C_{p} \rho_{0} \int_{z} \int_{x} \bar{v}\left[\overline{\%_{S T G}} \theta_{S T G}^{\prime}\right] d x d z
$$

and

$$
H T^{L a b}=C_{p} \rho_{0} \int_{z} \int_{x} \bar{v}\left[\overline{\%_{S P G}} \theta_{S P G}^{\prime}\right] d x d z
$$

(2) changes in the relative proportion (or volume) of the two source waters, computed as:

$$
H T^{\text {Ratio }}=C_{p} \rho_{0} \int_{z} \int_{x} \bar{v}\left[\%_{S T G}^{\prime} \overline{\theta_{S T G}}+\%_{S P G}^{\prime} \overline{\theta_{S P G}}\right] d x d z
$$

(3) changes in air-sea heat fluxes and/or mixing between the STG, SPG and A25-Ovide lines, computed as:

$$
H T^{\text {Path }}=C_{p} \rho_{0} \int_{z} \int_{x} \bar{v} \Delta \theta^{\prime} d x d z
$$

Mechanism (1), which refers to temperature anomalies in the source regions impacting the temperature field at A25-Ovide, is quantified in Figure 10. Interestingly, the integrated effects of $\mathrm{HT}^{\text {Subt }}$ and $\mathrm{HT}^{\mathrm{Lab}}$ show an out-ofphase relationship, the former (latter) inducing a cooling (warming) of the eastern SPG before the mid-1980's and a subsequent warming (cooling) until 2000. The resulting overall impact on the heat transport at A25-Ovide is consequently fairly small. This appears consistent with regional changes 

479 gyre.

in the magnitude of oceanic heat loss related to the NAO: weaker in the Labrador Sea and stronger in the subtropics for negative NAO conditions, and vice-versa for positive NAO periods (e.g. Häkkinen and Rhines, 2004).

Mechanism (2), which refers to changes in the horizontal gyre circulation impacting the temperature field at A25-Ovide, is quantified in Figure 11. Variations in $\%_{S T G}$ (or equivalently in $\%_{S P G}$ ) project onto the very strong temperature contrast between subtropical and subpolar water masses in their source regions $\left(\overline{\theta_{S T G}}-\overline{\theta_{S P G}}=11.7^{\circ} \mathrm{C}\right)$. The predominance of $\mathrm{HT}^{\text {Ratio }}$ in driving the strong $\mathrm{HC}$ trends prior and after the mid-1980's is striking. Note that de Boisséson et al. (2012) also highlighted the significance of this particular mechanism in driving hydrographic changes of the SPMW in the vicinity of Reykjanes Ridge. To support this result, we show in Figure 12 an Hovmöller diagram of $\%_{S T G}^{\prime}$ along A25-Ovide. Local anomalies of $\pm 10 \%$ are observed between $50^{\circ} \mathrm{N}$ and $57^{\circ} \mathrm{N}$ where a substantial $\mathrm{HT}_{\theta}$ signal was revealed in the Eulerian framework (see Figure 4.8 in Desbruyères (2013)). This local positive trend in \%'STG observed from the 1970's to the late 1990's is consistent with an intensification of the northern NAC branch primarily driven by an increased contribution of its subtropical component, as reported by Desbruyères et al. (2013). The negative anomalies observed north of $50^{\circ} \mathrm{N}$ since 2001 reflect a decreasing transport of subtropical water masses within the northern NAC branch. As suggested in Chaudhuri et al. (2011) and confirmed in Desbruyères et al. (2013), this weakening of the subtropical inflow occurred concomitantly with a northeastward expansion of the subtropical

480 Mechanism (3), which refers to temperature anomalies that do not di- 
rectly depends on the initial properties (transport and temperature) of the subtropical and subpolar water masses, is Figure 13. Its impact on the heat content of the eastern SPG is a warming in the late 1960's and early 1970's, a gradual cooling trend until late 1990's and a relatively sharp warming in the 2000's. To a first approximation, the temporal behavior of $\mathrm{HT}^{\text {Path }}$ should be related to anomalous air-sea heat fluxes along the water masses path between the STG, SPG and A25-Ovide sections. To verify this, the integrated HT ${ }^{\text {Path }}$ signal is compared with the heat content variability induced by air-sea heat fluxes between the three sections (Figure 13). Although the magnitude of both signals cannot be quantitatively compared (the pathways of the numerical particles do not cover the whole domain), their temporal behaviors are in fairly good agreement $(r=0.86)$. Therefore, air-sea heat fluxes act as a strong damping mechanisms of temperature anomalies formed via changes in the horizontal circulation upstream of A25-Ovide (mechanism 2).

\section{Conclusion}

The low-frequency variability of the heat content in the eastern SPG region has been investigated in the ORCA025-G70 simulation for the period 1965-2004. The present simulation was shown to reproduce a consistent interannual-decadal signal close to observational estimates. The 40-year timeseries of heat content anomalies within a box bounded by the A25-Ovide section and the Greenland-Iceland-Scotland sills revealed two periods of significant changes within the upper few hundred meters of the water column: a strong cooling during the 1960 and early 1970's and a strong warming in the 1990 and early 2000's. A heat budget calculation within the considered 
domain points the oceanic heat transport variability across the A25-Ovide section as the main contributor to heat content decadal variations, in agreement with previous modeling studies (e.g. Hátún et al., 2005; Marsh et al., 2008). The impact of air-sea heat fluxes is a delayed (1-3 years) damping of heat content trends, as already suggested by Grist et al. (2010). A temporal decomposition of the heat transport at A25-Ovide was then performed and the Lagrangian analysis tool ARIANE was used to complement the Eulerian investigations. Accordingly, we list the following conclusions:

- Heat transport variability at A25-Ovide results from an imbalance between opposed changes in its velocity and temperature components. Temperature and velocity anomalies are linked with each other through the heaves of isopycnal surfaces at A25-Ovide.

The respective impacts of velocity anomalies acting upon the mean temperature field and the advection of temperature anomalies by the mean circulation have been quantified. Remarkably, their associated signals are strongly anti-correlated. For instance, the well-documented period of the 1990's-2000's is marked by a strong warming of the eastern SPG occuring through a weakening of the circulation. A similar opposition between the contribution of $\mathrm{HT}_{v}$ and $\mathrm{HT}_{\theta}$ to heat content changes along the NAC pathway was also reported by Krahmann et al. (2000). While $\mathrm{HT}_{v}$ and $\mathrm{HT}_{\theta}$ are both important in driving the decadal variability of $\mathrm{HC}$ in the eastern SPG, the role of temperature anomalies overcomes that of velocity anomalies during the whole period (see figure 4).

The thermally-driven heat transport at A25-Ovide is presumably associ- 
ated with changes in the depth of isopycnal surfaces (heaving) rather than density-compensated temperature changes (spiciness). This is in line with the study of Palmer and Haines (2009) who showed an important impact of isopycnal heaving on heat content change in the North Atlantic. Here, the heaves of the main pycnocline along the section are characterized by significant decadal fluctuations east of Reykjanes Ridge. They are associated with large-scale changes in the slope of the pycnocline, driving significant velocity and associated heat transport anomalies and thereby explaining the strong opposition between $\mathrm{HT}_{v}$ and $\mathrm{HT}_{\theta}$. In other words, the advection of positive temperature anomalies from the western basin is associated with a deepening of the main pycnocline in the Iceland Basin (1990's), thereby inducing negative velocity anomalies through a decay of the pycnocline slope, and vice versa for the advection of negative temperature anomalies by the NAC (1970's).

- Temperature anomalies advected by the mean currents across A25-Ovide are closely related to the varying proportion of cold subpolar waters and warm subtropical waters within the NAC. Air-sea heat fluxes south of A25-Ovide act as a damping mechanism.

The temperature component of the heat transport at A25-Ovide was satisfactorily reconstructed using a Lagrangian analysis tool, which gave access to additionnal information regarding the two main source waters feeding the NAC: the subpolar contribution from the Labrador Sea and the subtropical contribution from the Gulf Stream. Temperature anomalies advected across A25-Ovide are shown to result from several causes. Amongst them, decadal 
changes in the relative proportion of subtropical and subpolar water masses advected within the NAC stand as the dominant contributor to the thermal component of heat transport variability across the A25-Ovide section, in line with de Boisséson et al. (2012). Here, we show that the anomalous gyre circulation mostly impacts the temperature content of the northern NAC branch north of about $50^{\circ} \mathrm{N}$, through a northward shift of the subtropical inflow within the NAC (Desbruyères et al., 2013). This decadal evolution of the NAC structure and composition appears consistent with a northward shift of the windstress curl climatological pattern following a positive trend in the NAO index (Marshall et al., 2001; Herbaut and Houssais, 2009). Note that Zhai and Sheldon (2012) also pointed out the altered wind-driven horizontal circulation as the dominant source of decadal heat content changes in the North Atlantic. These temperature anomalies formed through changes in the gyre circulation are damped by air-sea heat fluxes along the water mass paths toward the eastern SPG. The advection of remote temperature anomalies from the distinct source regions has an overall weak impact on the heat transport at A25-Ovide. In fact, the respective temperature anomalies from the Labrador Sea and the subtropics strongly compensate for each other at A25-Ovide, potentially reflecting increased (decreased) oceanic heat loss in the Labrador Sea (subtropics) following the positive NAO trend from the 1960's to the late 1990's (e.g Marshall et al., 2001; Curry and McCartney, 2001).

Past studies of temperature changes in the northeastern Atlantic were mainly based on Eulerian diagnosis, using hydrographic criterion to infer dynamical changes in the gyre circulation (Hátún et al., 2005). Accord- 
580

ingly, the observed warming from the mid-1990's was related to a buoyancydriven shrinking of the subpolar gyre following the sharp NAO drop in winter 1995/96. Here, the Lagrangian description of temperature changes at A25Ovide highlighted a different dominant mechanism, namely the progressive wind-driven northward shift of subtropical water masses within the NAC. Following a long-term positive trend in the NAO from the late 1970's, the magnitude of the oceanic heat transport reached its maximum in the mid1990's, largely overcoming local oceanic heat loss to the atmosphere and inducing a strong warming of the upper oceanic layers in the northeastern Atlantic basin. 
590

acknowledgments The numerical simulation used in the present study has been performed in the framework of the DRAKKAR project. Damien Desbruyères is supported by CNRS and IFREMER, Virginie Thierry is supported by IFREMER and Herlé Mercier is supported by CNRS. This is a contribution to the OVIDE project supported by IFREMER, CNRS, INSU and French national programs (GMMC and LEFE-IDAO). The authors thank Bruno Blanke and Nicolas Grima for their help in performing the Lagrangian experiments. We also acknowledge two anonymous reviewers for their help in improving the manuscript. 


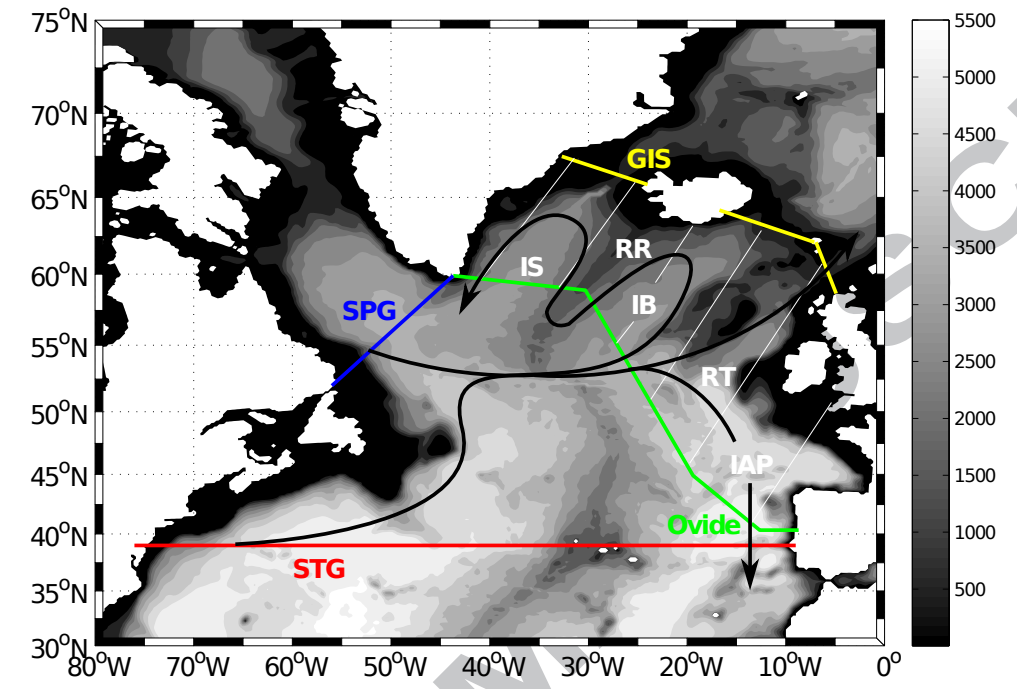

Figure 1: Bathymetry of the northern North Atlantic (in m) and positions of the sections discussed in the text: the A25-Ovide section (green), the STG transect (red), the SPG transect (blue), and the GIS section (yellow). The heat budget calculation presented in Section 3 is performed within the hatched domain. The main basins and topographic features mentioned in the text are labeled as: IS (Irminger Sea), IB (Iceland Basin), RT (Rockall Trough), IAP (Iberian Abyssal Plain), RR (Reykjanes Ridge). The black lines stand for a simplified view of the main pathways of the North Atlantic Current. 
(a)

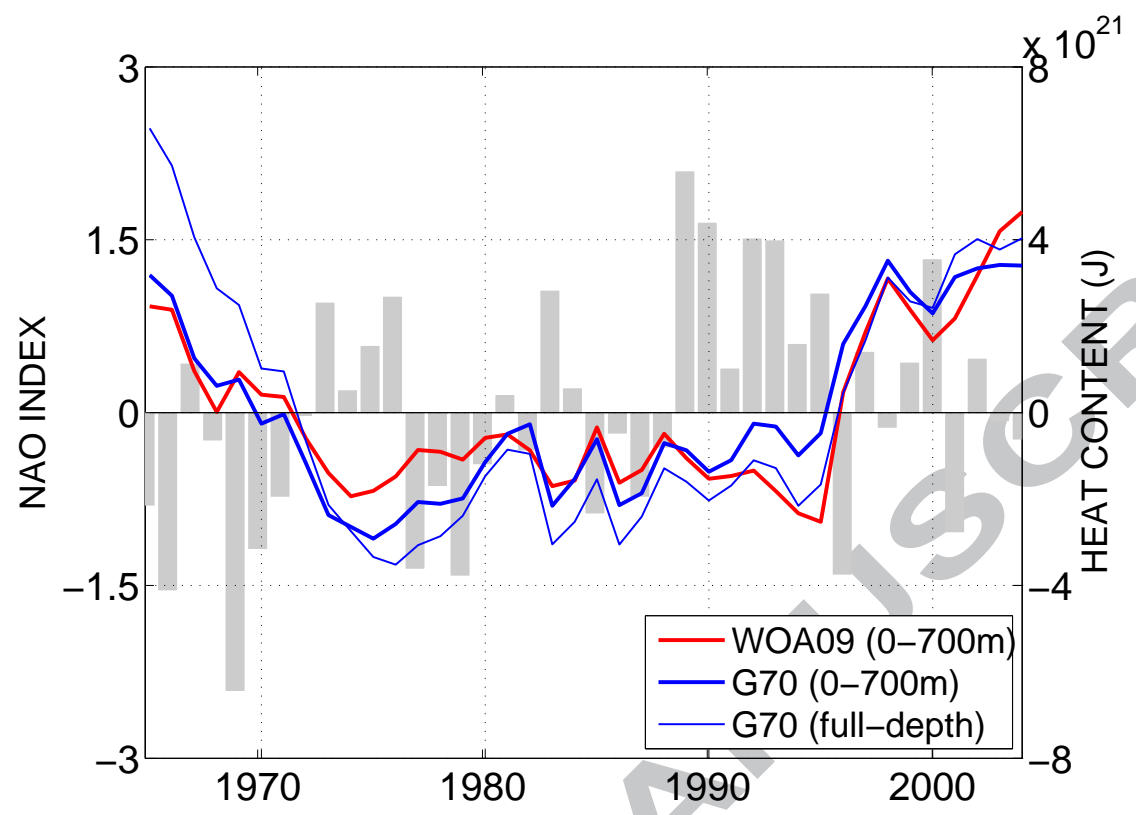

(b)

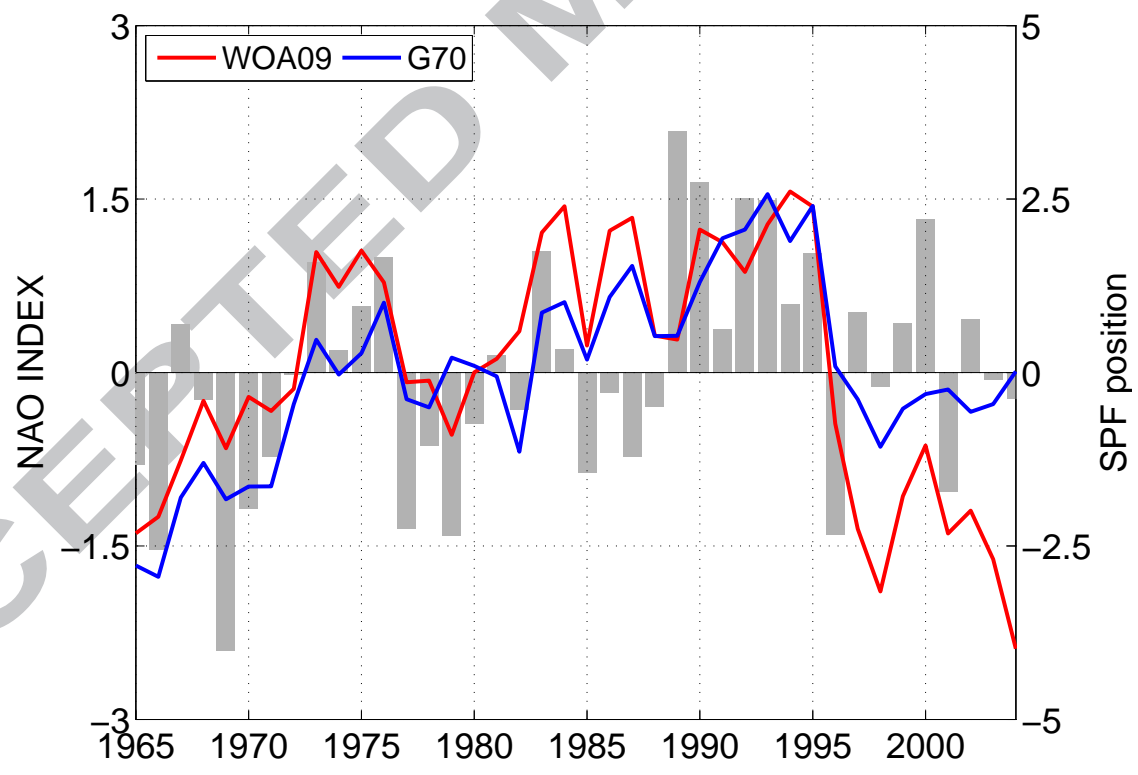

Figure 2: Heat content anomalies $(\mathrm{J})$ within the eastern SPG (domain bounded by the A25-Ovide and GIS sections) and for the 0-700m layer for ORCA025-G70 (thick blue) and WOD09 (thick red). HC anomalies within the whole water column in ORCA025-G70 are also shown (thin blue). (b) Anomalies in the longitudinal position (in ${ }^{\circ}$ ) of the subpolar front at $58^{\circ} \mathrm{N}$ (defined by the $8^{\circ} \mathrm{C}$ isotherm at 200m) in ORCA025-G70 (blue) and WOD09 (red). Positive (negative) anomalies indicate an eastward (westward) shift of the subpolar front. The gray bars indicate the normalized NAO index. 
(a)

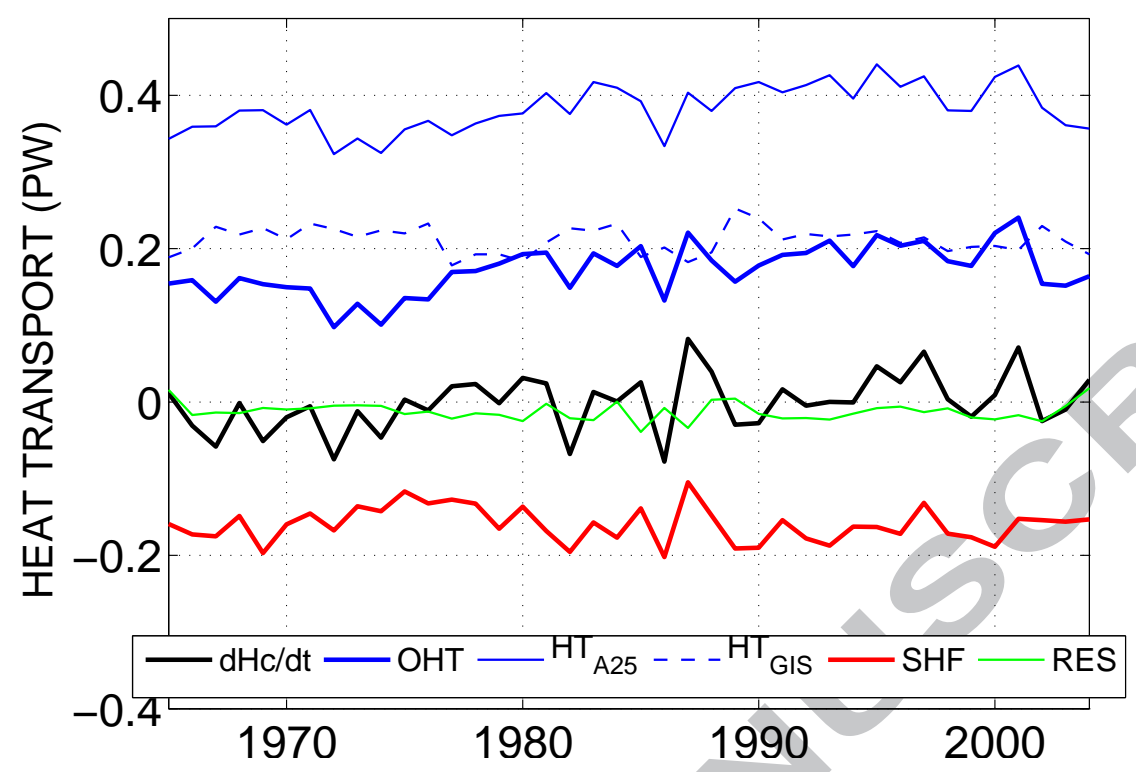

(b)

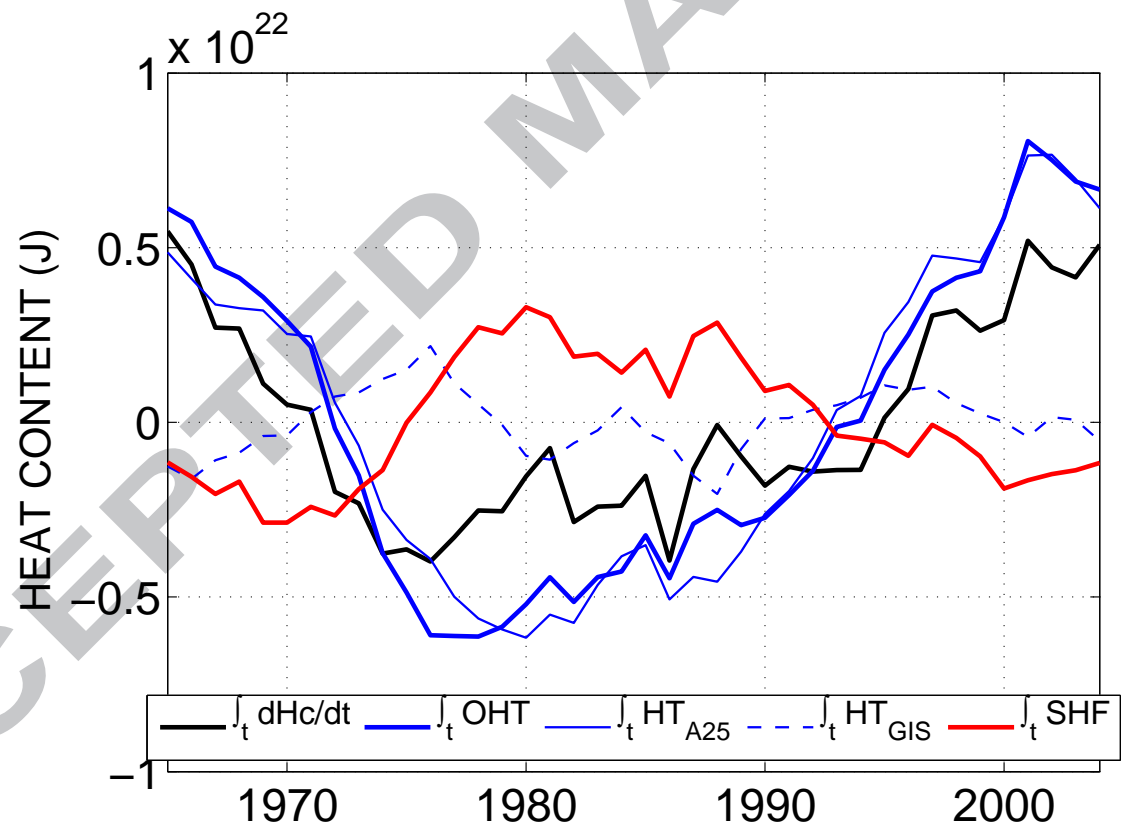

Figure 3: (a) Heat budget components (in PW): heat content rate of change (black, $\int_{t} d H c / d t d t$ ), air-sea heat flux (red, $\int_{t} S H F d t$, negative sign indicates a heat transfer from the ocean to the atmosphere) and heat transport convergence (blue, $\int_{t} O H T d t$ ). The latter is decomposed between the heat transport across the A25-Ovide section (thin blue, $\int_{t} H T_{A 25} d t$ ) and across the Greenland-Iceland-Scotland sills (thin dashed blue, $\left.\int_{t} H T_{G I S} d t\right)$. The green line stands for residual terms needed to close the budget. (b) Same as (a) but expressed as a heat content change (in J). Heat flux anomalies are integrated in time from their initial (absolute) value of 1965. The residual line was omitted for clarity. 


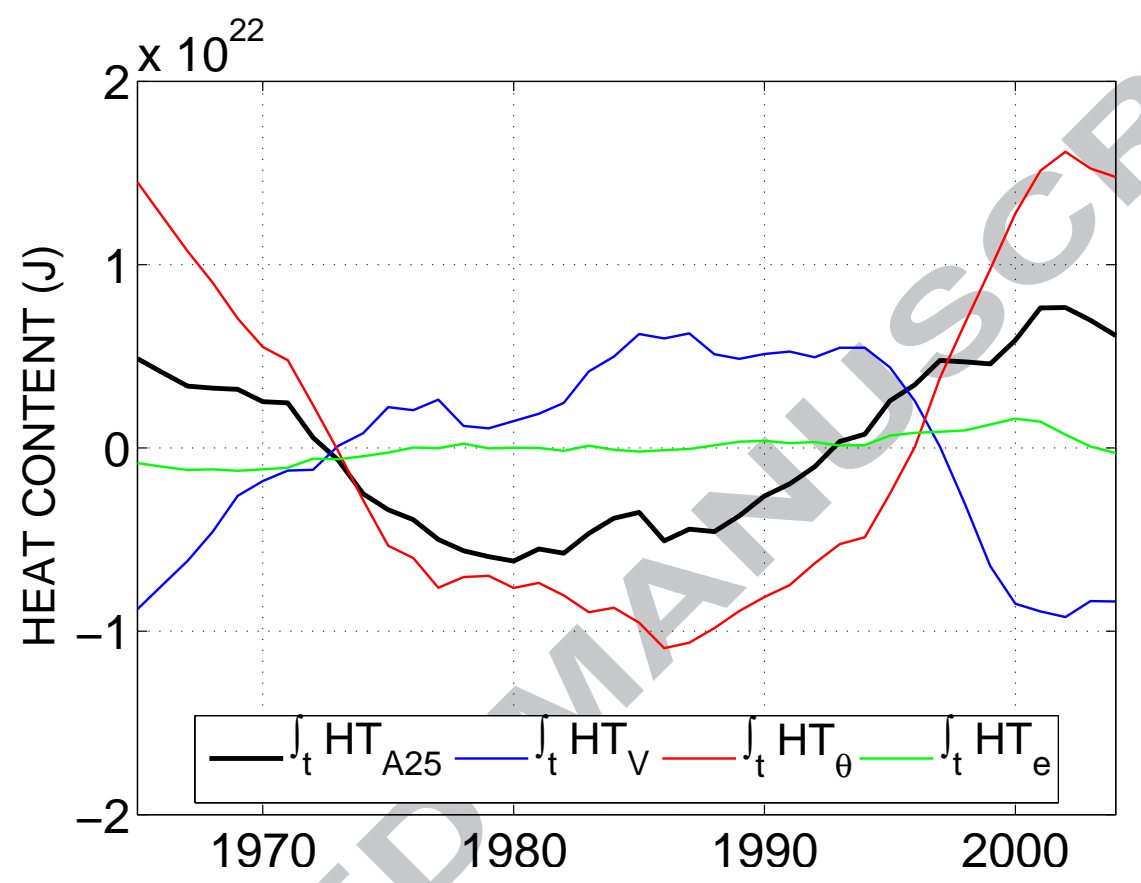

Figure 4: Temporal decomposition of the (integrated) heat transport (in J) at A25-Ovide (black, $\left.\int_{t} H T_{A 25} d t\right)$ into a velocity component $\left(v^{\prime} \bar{\theta}\right.$, blue, $\left.\int_{t} H T_{v} d t\right)$, a temperature component $\left(\bar{v} \theta^{\prime}\right.$, red, $\left.\int_{t} H T_{\theta} d t\right)$ and an eddy component $\left(v^{\prime} \theta^{\prime}\right.$, green, $\left.\int_{t} H T_{e} d t\right)$. Heat flux anomalies are integrated in time from their initial (absolute) value of 1965. 


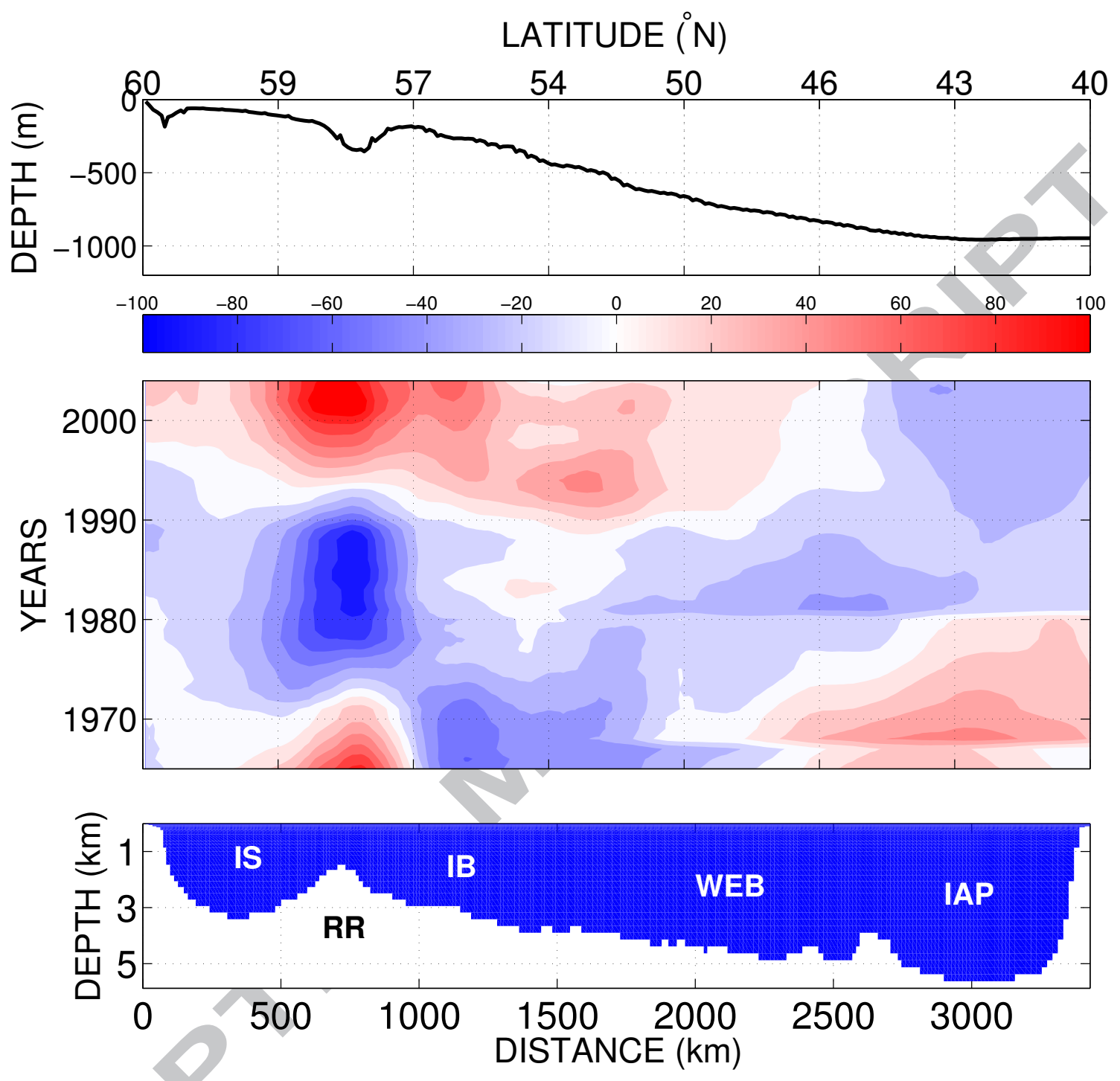

Figure 5: Top: mean depth of $\sigma_{m}\left(\sigma_{1}=32.1\right)$ along A25-Ovide. Middle: time-latitude diagram of the vertical displacements of $\sigma_{m}$ (in m) along A25-Ovide. Positive (negative) anomalies indicate an downward (upward) displacement of the main pycnocline. Bottom: bathymetry along the section with the following labels: RR (Reykjanes Ridge), IS (Irminger Sea), IB (Iceland Basin), WEB (West European Basin) and IAP (Iberian Abyssal Plain). 


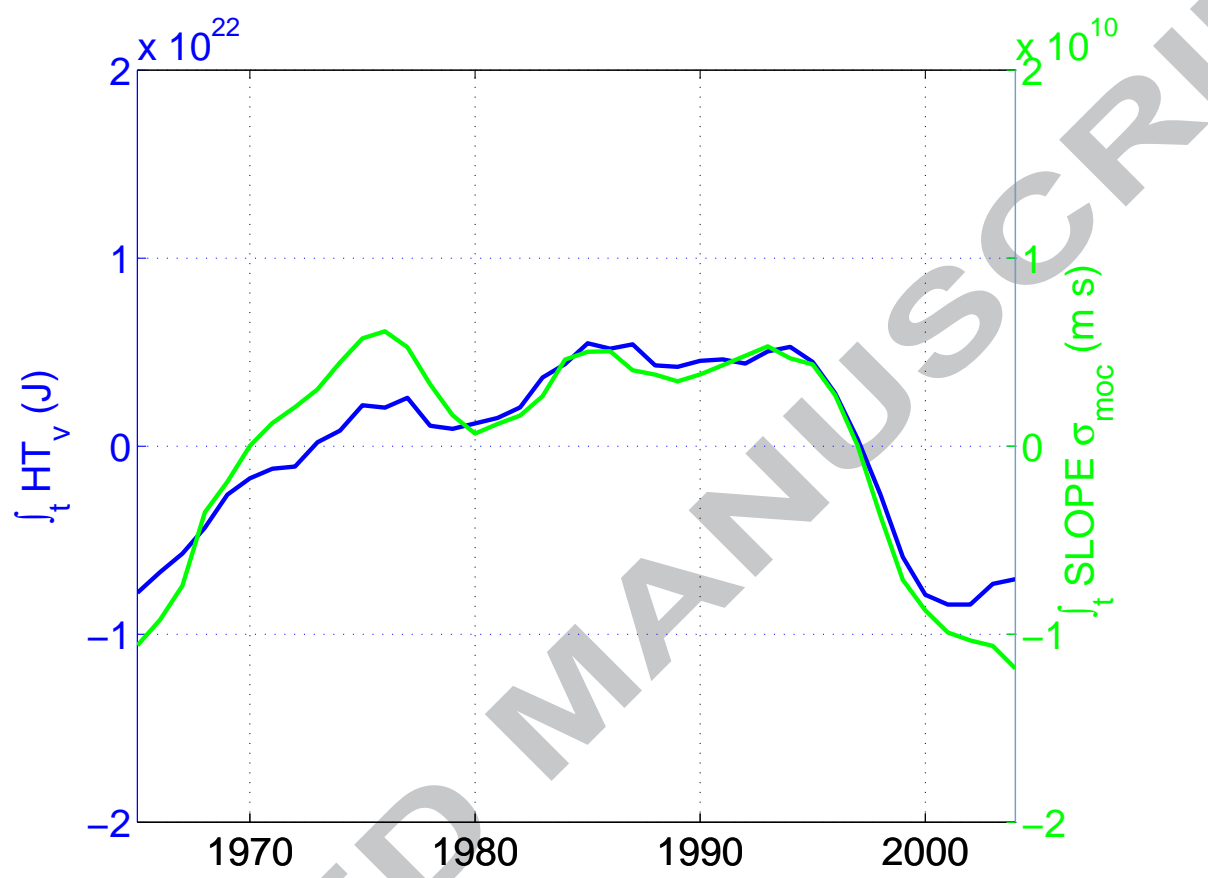

Figure 6: Comparison of the (integrated) velocity component of the heat transport at A25-Ovide (blue) with an (integrated) index of the pycnocline slope east of Reykjanes Ridge (green, in $\mathrm{m} \mathrm{s}$ ). The latter is defined by the difference in the depth of $\sigma_{m}$ averaged north and south of $50^{\circ} \mathrm{N}$. 
(a)

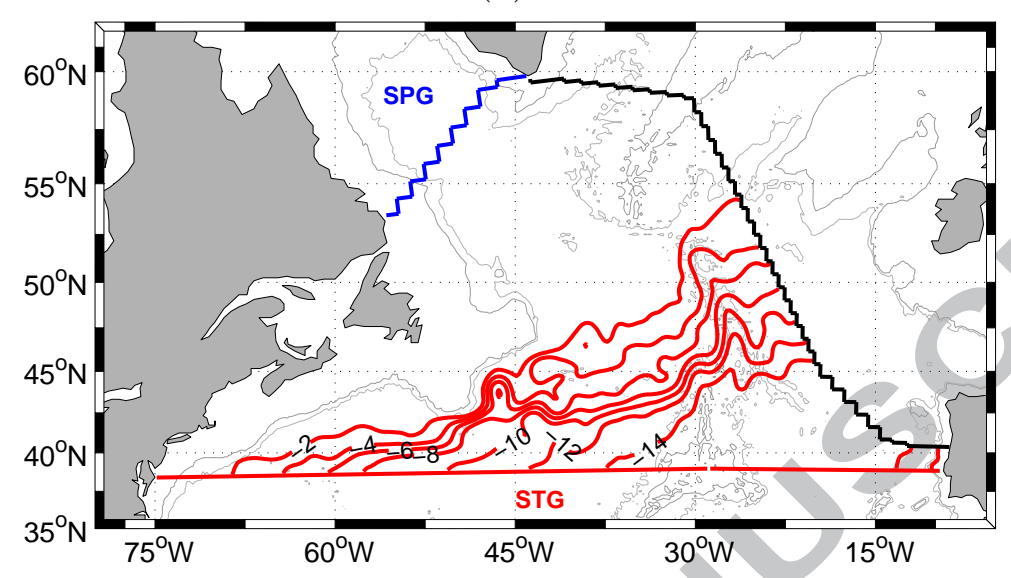

(b)

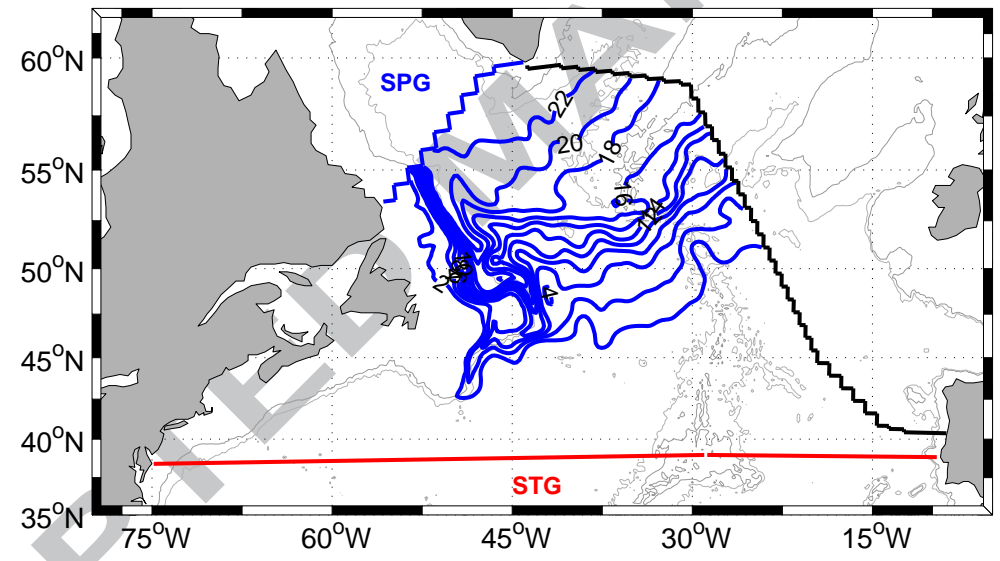

Figure 7: Mean (1965-2004) horizontal streamfunction (Sv) of the (a) subtropical and (b) subpolar components of the NAC transport across A25-Ovide deduced from the Lagrangian experiments. Contour interval is $2 \mathrm{~Sv}$. 


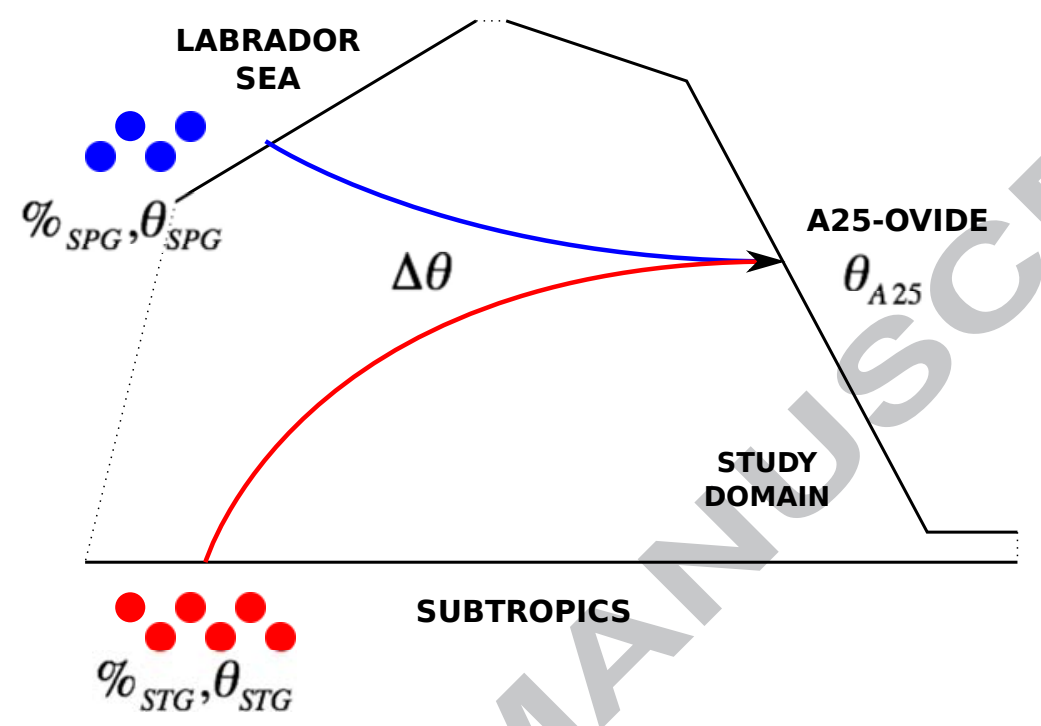

Figure 8: Methodology for estimating the Lagrangian temperature within individual bins along A25-Ovide. As an example, consider a bin at A25-Ovide that contains $\%_{S T G}=$ $60 \%$ of subtropical particles having a source temperature $\theta_{S T G}=14^{\circ} \mathrm{C}$, and $\%_{S P G}=40 \%$ of subpolar particles having a source temperature $\theta_{S P G}=4^{\circ} \mathrm{C}$. According to equation 6 , if the resulting mixture is cooled by $\Delta \theta=1^{\circ} \mathrm{C}$ between the three sections (by air-sea heat fluxes and/or lateral mixing), the temperature at A25-Ovide will be $\theta_{A 25}=0.6^{*} 14+$ $0.4^{*} 4-1=9^{\circ} \mathrm{C}$. This methodology is applied for each bin along A25-Ovide every month between 1965 and 2004. 


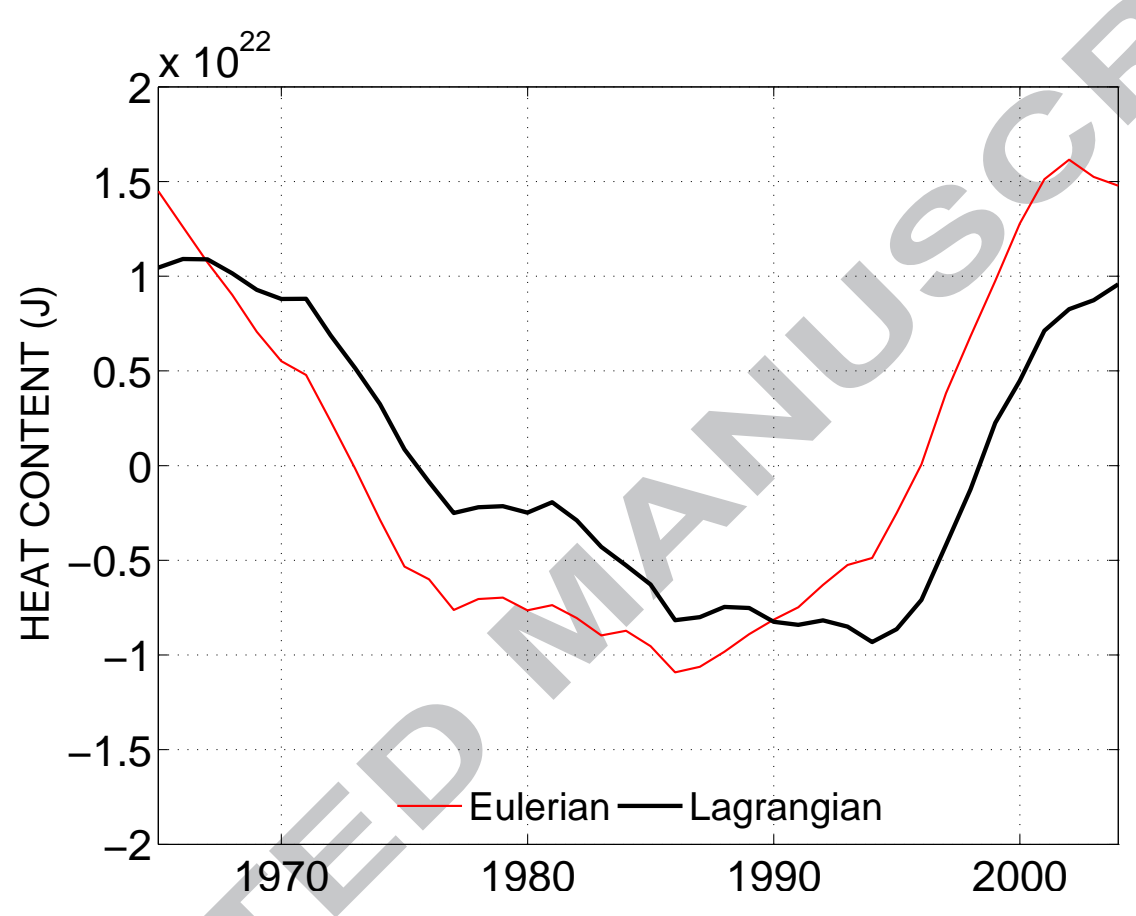

Figure 9: Comparison of the (integrated) thermally-driven heat transport $\mathrm{HT}_{\theta}(\mathrm{J})$ in the Eulerian (red) and Lagrangian (black) frameworks. 


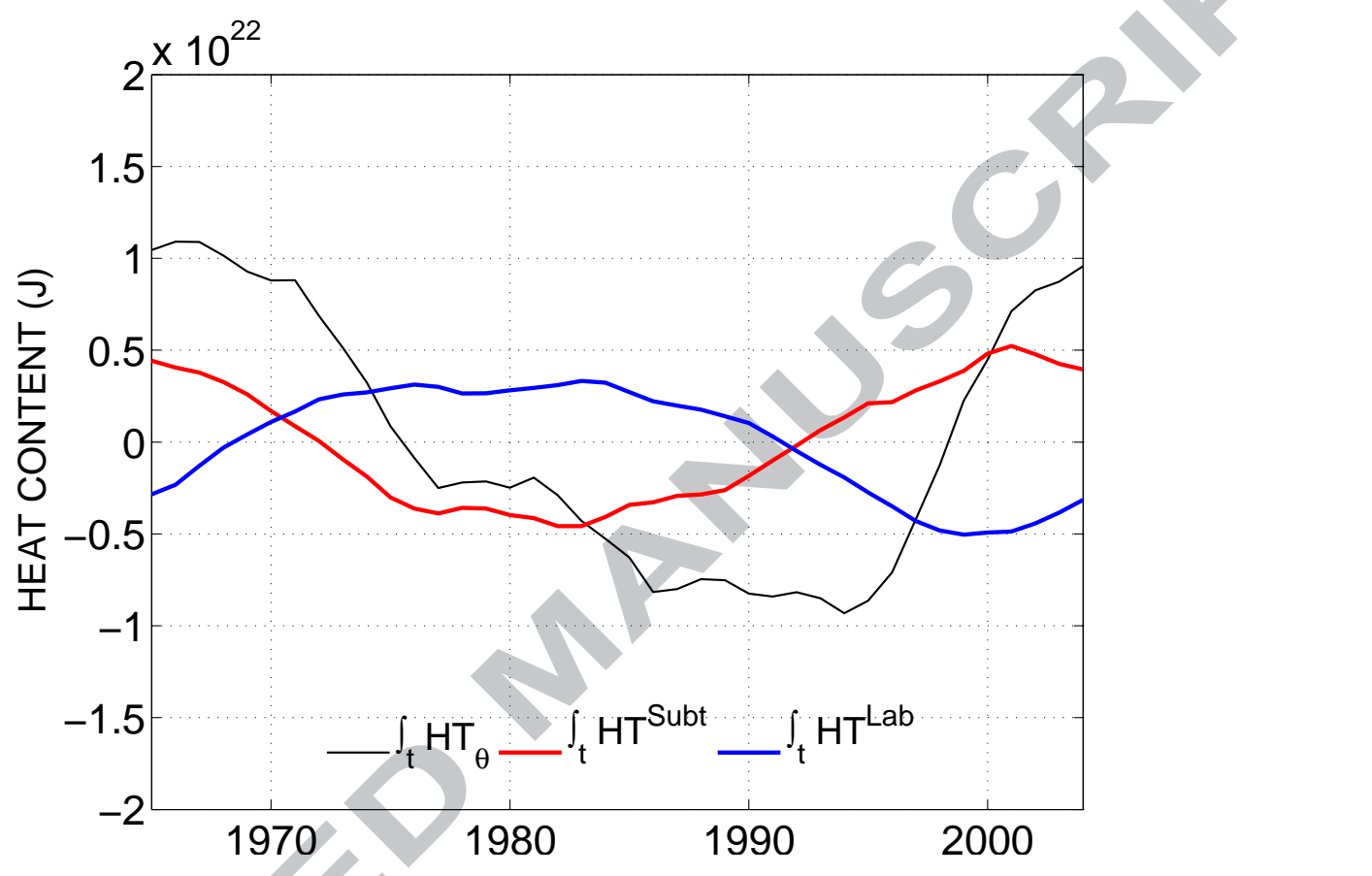

Figure 10: Time-integrated contribution of $\mathrm{HT}^{\text {Subt }}$ (red; temperature anomalies advected from the subtropics) and $\mathrm{HT}^{\mathrm{Lab}}$ (blue; temperature anomalies advected from the Labrador Sea) to the Lagrangian $\mathrm{HT}_{\theta}$ (black). Units are in $\mathrm{J}$. 


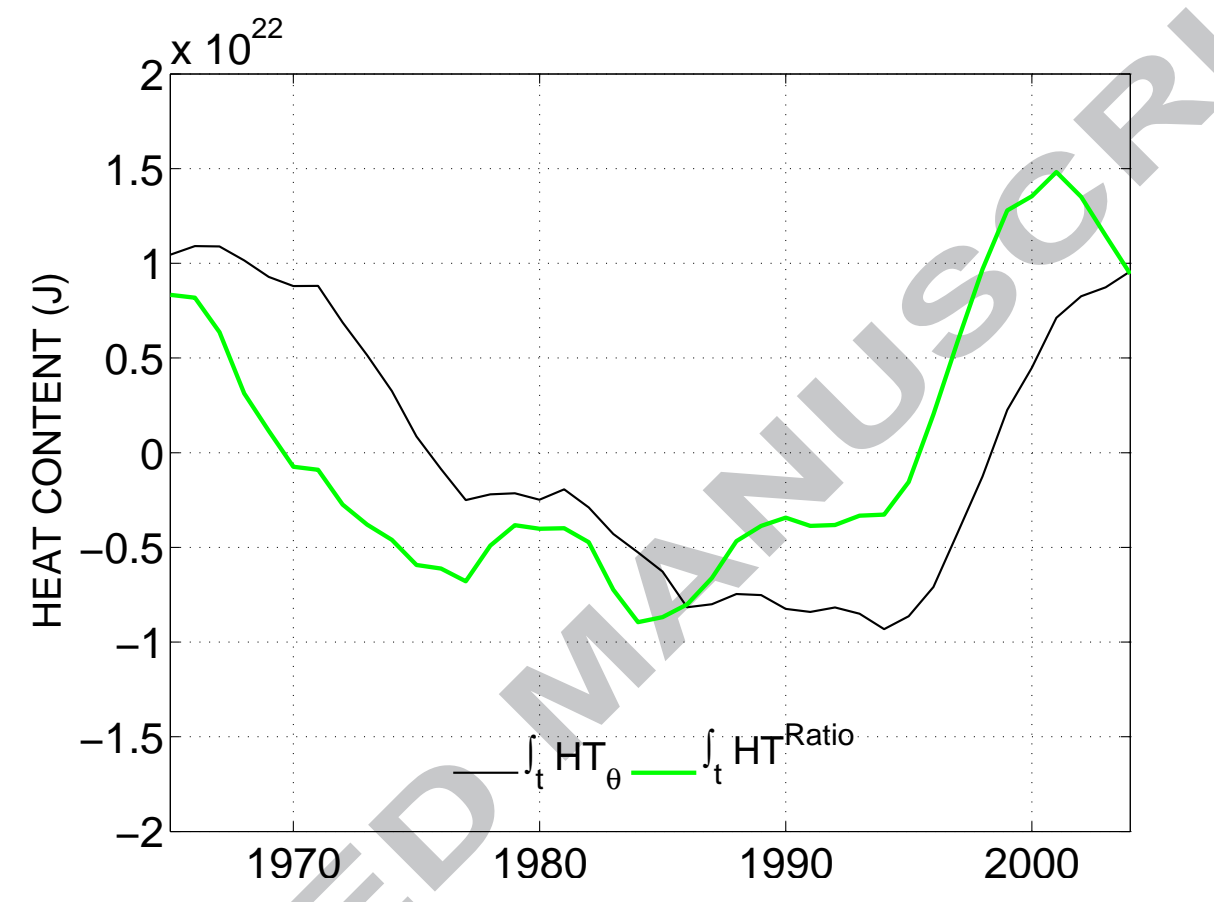

Figure 11: Time-integrated contribution of $\mathrm{HT}^{\text {Ratio }}$ (green; temperature anomalies associated with the relative proportion of subtropical and subpolar water masses) to the Lagrangian $\mathrm{HT}_{\theta}$ (black) . Units are in J. 


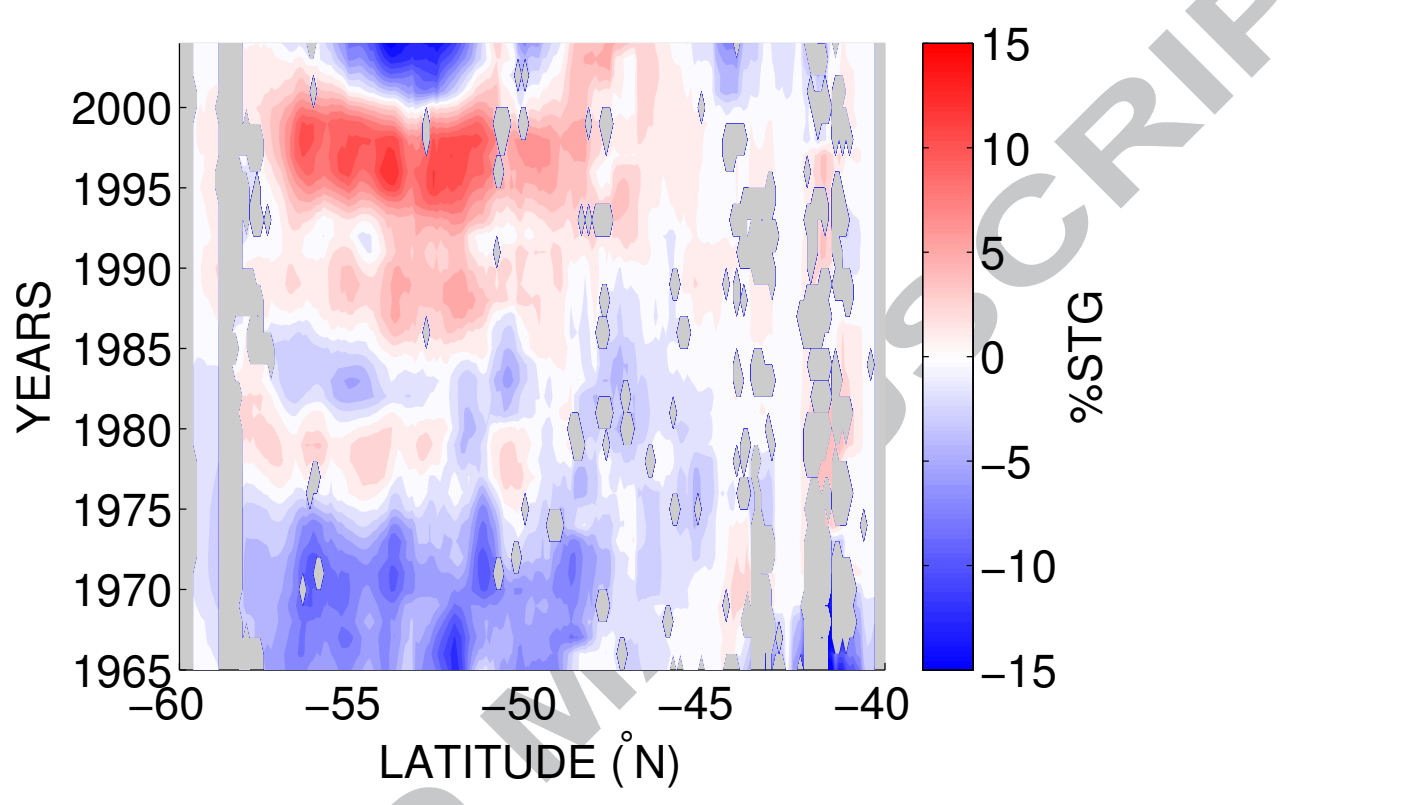

Figure 12: Time-latitude diagram of anomalies in the relative proportion of subtropical water masses along A25-Ovide (in \%). The $\%_{S T G}$ ratio has been calculated within individual latitudinal bins $\left(0.1^{\circ}\right)$. Gray shadings indicate regions where the seeded particles are not including in the STG or SPG group (e.g. the recirculation around Reykjanes Ridge or the southward flow in the Iberian Abyssal Plain). 


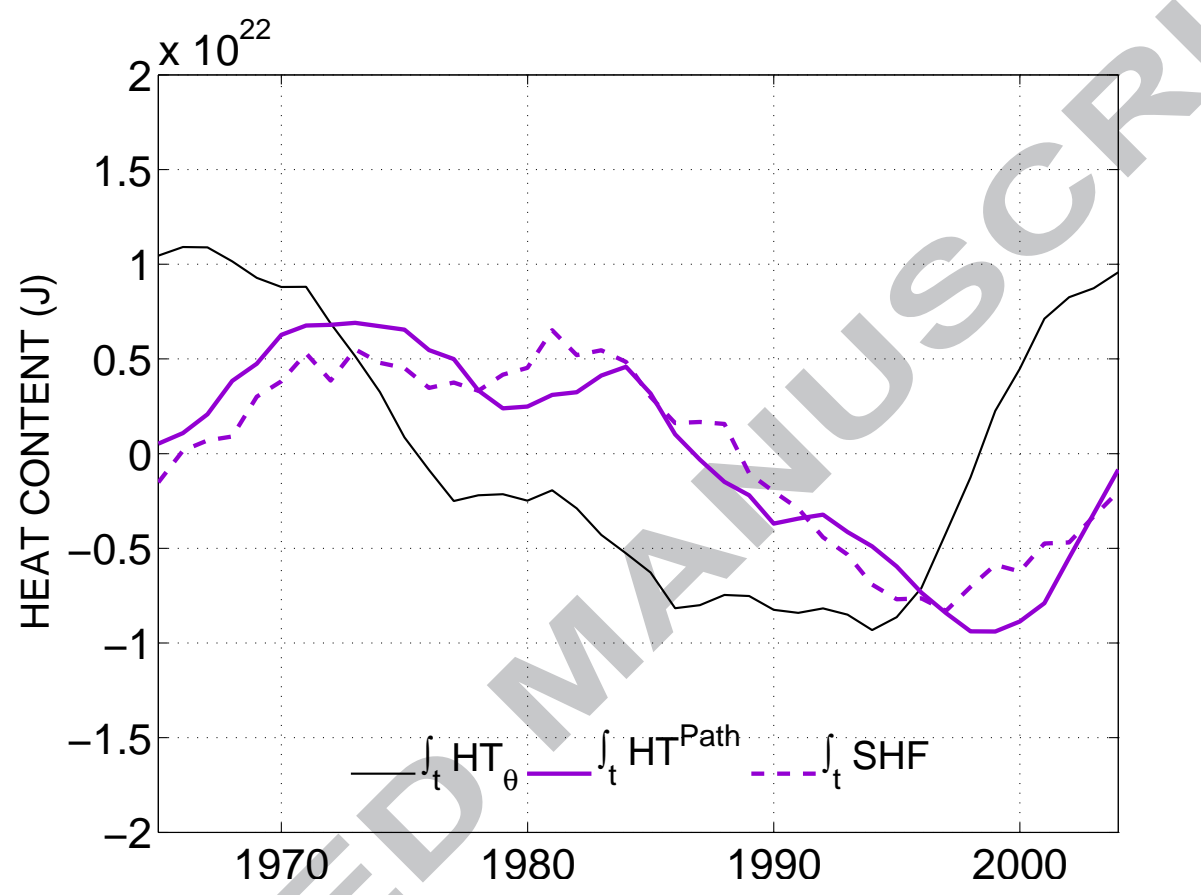

Figure 13: Time-integrated contribution of $\mathrm{HT}^{\text {Path }}$ (solid cyan) to the Lagrangian $\mathrm{HT}_{\theta}$ (black) of $\mathrm{HT}^{\text {Path }}$ (solid cyan). The dashed cyan line is a time series of heat content anomalies induced by anomalous air-sea heat fluxes within the region bounded by the A25-Ovide, STG and SPG sections (the signal was divided by 50). Units are in J. 


\section{References}

Barnier, B., Madec, G., Penduff, T., Molines, J.-M., Tréguier, A.-M., Sommer, J. L., Beckmann, A., Biastoch, A., Böning, C., Dengg, J., Derval, C., Durand, E., Gulev, S., Remy, E., Talandier, C., Theetten, S., Maltrud, M., McLean, J., Cuevas, B. D., 2006. Impact of partial steps and momentum advection schemes in a global ocean circulation model at eddy-permitting resolution. Ocean Dynamics 56, 543-567.

Bersh, M., 2002. North Atlantic Oscillation-induced changes of the upper layer circulation in the northern North Atlantic Ocean. Journal of Geophysical Research 107 (C10), 223-235.

Blanke, B., Arhan, M., Madec, G., Roche, S., 1999. Warm water paths in the equatorial Atlantic as diagnosed with a general circulation model. Journal of Physical Oceanography 29 (11), 2753-2768.

Blanke, B., Raynaud, S., 1997. Kinematics of the Pacific Equatorial Undercurrent: An Eulerian and Lagrangian Approach from GCM Results. Journal of Physical Oceanography 27 (6), 1038-1053.

Böning, C., Scheinert, M., Dengg, J., Biastoch, A., Funk, A., 2006. Decadal variability of subpolar gyre transport and its reverberation in the North Atlantic overturning. Geophysical Research Letters 33 (L21S01).

Boyer, T. P., Antonov, J. I., Garcia, H. E., Johnson, D. R., Locarnini, R. A., Mishonov, A. V., Pitcher, M. T., Baranova, O. K., Smolyar, I. V., 2006. World Ocean Database 2005. S. Levitus, Ed., NOAA Atlas NESDIS 60. U.S. Government Printing Office, Washington, D.C., 190 pp., DVDs. 
Brambilla, E., Talley, L. D., 2008. Subpolar Mode Water in the northeastern Atlantic: 1. Averaged properties and mean circulation. Journal of Geophysical Research 113 (C04025).

Brodeau, L., Barnier, B., Penduff, T., Tréguier, A.-M., Gulev, S., 2009. An evaluation of ERA-40 and CORE atmospheric variables as drivers of global ocean models. Ocean Modelling 31, 88-104.

Burkholder, K. C., Lozier, M. S., 2011. Mid-depth Lagrangian Pathways in the North Atlantic and their impact on the Salinity of the Eastern Subpolar Gyre. Deep-Sea Research I 58, 1196-1204.

Chaudhuri, A. H., Gangopadhyay, A., Bisagni, J. J., 2011. Contrasting response of the eastern and western North Atlantic circulation to an episodic climate event. Journal of Physical Oceanography 41 (9), 1630-1638.

Curry, R. G., McCartney, M. S., 2001. Ocean Gyre Circulation Changes Associated with the North Atlantic Oscillation. Journal of Physical Oceanography $31,3374-3400$.

de Boisséson, E., Thierry, V., Mercier, H., 2010. Mixed layer heat budget in the Iceland Basin from Argo. Journal of Geophysical Research 115 (C10055).

de Boisséson, E., Thierry, V., Mercier, H., Caniaux, G., Desbruyères, D., 2012. Origin, formation and variability of the Subpolar Mode Water observed over the Reykjanes Ridge. Journal of Geophysical Research.

Desbruyères, D., 2013. The meridional overturning circulation variability and 
heat content changes in the north atlantic subpolar the Meridional Overturning Circulation Variability and Heat Content Canges in the North Atlantic Subpolar Gyre. Ph.D. thesis, Université de Bretagne Occidentale.

Desbruyères, D., Mercier, H., Thierry, V., 2013. Simulated Decadal Variability of the Meridional Overturning Circulation across the A25-Ovide section. Journal of Geophysical Research.

Deshayes, J., Frankignoul, C., 2008. Simulated Variability of the Circulation in the North Atlantic from 1953 to 2003. Journal of Climate 21 (19), 49194933.

Eden, C., Willebrand, J., 2001. Mechanism of Interannual to Decadal Variability of the North Atlantic Circulation. Journal of Climate 14 (10), 22662280 .

Fichefet, T., Maqueda, M. A. M., 1999. Modelling the influence of snow accumulation and snow-ice formation on the seasonal cycle of the Antarctic sea-ice cover. Climate Dynamics 15 (4), 251-268.

Griffies, S. M., Biastoch, A., Böning, C., Bryan, F., Danabasoglu, G., Chassignet, E. P., England, M. H., Gerdes, R., Haak, H., Hallberg, R. W., Hazeleger, W., Jungclaus, J., Large, W. G., Madec, G., Pirani, A., Samuels, B. L., Scheinert, M., Gupta, A. S., Severijns, C. A., Simmons, H. L., Treguier, A.-M., Winton, M., Yeager, S., Yin, J., 2009. Coordinated Ocean-ice Reference Experiments (COREs). Ocean Modelling 26 (1-2), 146. 
Grist, J. P., Josey, S. A., Marsh, R., Good, S. A., Coward, A. C., de Cuevas, B. A., Alderson, S. G., New, A. L., Madec, G., 2010. The roles of surface heat flux and ocean heat transport convergence in determining Atlantic Ocean temperature variability. Climate Dynamics 60 (4), 771-790.

Häkkinen, S., 1999. Variability of the simulated meridional heat transport in the North Atlantic for the period 1951-1993. Journal of Geophysical Research 104 (C5).

Häkkinen, S., Rhines, P. B., 2004. Decline of the Subpolar North Atlantic Circulation During the 1990s. Science 304 (5670), 555-559.

Häkkinen, S., Rhines, P. B., 2009. Shifting Surface Current in the northern North Atlantic Ocean. Journal of Geophysical Research 114 (C04005).

Hall, N. M. J., Barnier, B., Penduff, T., Molines, J. M., 2004. Interannual variation of Gulf Stream heat transport in a high-resolution model forced by reanalysis data. Climate Dynamics 23 (3-4), 341-351.

Hátún, H., Sandø, A. B., Drange, H., Hansen, B., Valdimarsson, H., 2005. Influence of the Atlantic Subpolar Gyre on the Thermohaline Circulation. Science 309 (5742), 1841-1844.

Herbaut, C., Houssais, M.-N., 2009. Response of the eastern North Atlantic subpolar gyre to the North Atlantic Oscillation. Geophysical Research Letters 36 (L17607).

Holliday, N. P., 2003. Air-sea interaction and circulation changes in the northeast Atlantic. Journal of Geophysical Research 108 (3259). 
Holliday, N. P., hughes, S. L., bacon, S., Beszczynska-Möller, A., Hansen, B., Lavìn, A., Loeng, H., Mork, K. A., Osterhus, S., Sherwin, T., Walczowski, W., 2008. Reversal of the 1960s to 1990s freshening trend in the northeast North Atlantic and Nordic Seas. Geophysical Research Letters 35 (L03614).

Hurrell, J. W., 1995. Decadal trends in the North Atlantic Oscillation: Regional temperatures and precipitation. Science 269, 676-679.

Krahmann, G., Visbeck, M., Reverdin, G., 2000. Formation and Propagation of Temperature Anomalies along the North Atlantic Current. Journal of Physical Oceanography 31, 1287-1303.

Large, W., Yeager, S., 2004. Diurnal to decadal global forcing for ocean and sea-ice models: The datasets and flux climatologies. Note NCAR/tn, Natl. Cent. for Atmos. Res., Boulder, Colo.

Levitus, S., Antonov, J. I., Boyer, T. P., Baranova, O. K., Garcia, H. E., Locarnini, R. A., Mishonov, A. V., Reagan, J. R., Seidov, D., Yarosh, E. S., Zweng, M. M., 2012. World ocean heat content and thermosteric sea level change (0-2000 m), 1955-2010. Geophysical Research Letters 39.

Levitus, S., Antonov, J. I., Boyer, T. P., Locarnini, R. A., Garcia, H. E., Mishonov, A. V., 2009. Global ocean heat content 1955-2008 in light of recently revealed instrumentation problems. Geophysical Research Letters 36 (L07608).

709 Levitus, S., Boyer, T. P., Conkright, M. E., O'Brien, T., Antonov, J., 
Stephens, C., Stathoplos, L., Johnson, D., Gelfeld, R., 1998. World Ocean Database 1998. NOAA Atlas NESDIS 18.

Lherminier, P., Mercier, H., Huck, T., Gourcuff, C., Perez, F. F., Morin, P., Sarafanov, A., Falina, A., 2010. The Atlantic Meridional Overturning Circulation and the Subpolar Gyre observed at the A25-OVIDE Section in June 2002 and 2004. Deep-Sea Research I 57 (11), 1374-1391.

Lozier, M. S., Leadbetter, S., Williams, R. G., Roussenov, V., Reed, M. S. C., Moore, N. J., 2008. The Spatial Pattern and Mechanisms of Heat-Content Change in the North Atlantic. Science 319 (5864), 800-803.

Madec, G., 2008. NEMO Ocean engine. Tech. rep., Institut Pierre-Simon Laplace.

Marsh, R., Josey, S. A., de Cuevas, B. A., Redbourn, L. J., Quartly, G. D., 2008. Mechanisms for recent warming of the North Atlantic: Insights gained with an eddy-permitting model. Journal of Geophysical Research 113 (C04031).

Marshall, J., Johnson, H,, Goodman, J., 2001. A study of the Interaction of the North Atlantic Oscillation with Ocean Circulation. Journal of Physical Oceanography 14 (7), 1399-1421.

Molines, J. M., Barnier, B., Penduff, T., Brodeau, L., Treguier, A. M., Theeten, S., Madec, G., 2006. Definition of the interannual experiment ORCA025-G70, 1958-2004. LEGI Report. 
Palmer, M. D., Haines, K., 2009. Estimating Oceanic Heat Content Change Using Isotherms. Journal of Climate 22, 4953-4969.

Rattan, S., Myers, P. G., Treguier, A.-M., Theetten, S., Biastoch, A., Böning, C., 2010. Towards an understanding of Labrador Sea salinity drift in eddypermitting simulations. Ocean Modelling 35 (1-2), 77-88.

Steele, M., Morley, R., Ermold, W., 2001. PHC: A global ocean hydrography with a high quality Arctic Ocean. Journal of Climate 14 (9), 2079-2087.

Thierry, V., Boisséson, E. D., Mercier, H., 2008. Interannual variability of the Subpolar Mode Water properties over the Reykjanes Ridge during 1990-2006. Journal of Geophysical Research 113 (C04016).

Treguier, A., Gourcuff, C., Lherminier, P., Mercier, H., Barnier, B., Madec, G., Molines, J.-M., Penduff, T., Czeschel, L., Böning, C., 2006. Internal and forced variability along a section between Greenland and Portugal in the CLIPPER Atlantic model. Ocean Dynamics 56 (5-6), 568-580.

Treguier, A.-M., England, M. H., Rintoul, S. R., Madec, G., Sommer, J. L., Molines, J. M., 2007. Southern Ocean overturning across streamlines in an eddying simulation of the Antarctic Circumpolar Current. Ocean Science $3,491-507$.

Zhai, X., Sheldon, L., 2012. On the North Atlantic Ocean Heat Content Change between 1955-70 and 1980-95. Journal of Climate 25 (10), 36193628. 